This document is confidential and is proprietary to the American Chemical Society and its authors. Do not copy or disclose without written permission. If you have received this item in error, notify the sender and delete all copies.

\title{
Para-Fluoro Postpolymerization Chemistry of Poly(pentafluorobenzyl methacrylate): Modification with Amines, Thiols, and Carbonylthiolates
}

\begin{tabular}{|r|l|}
\hline Journal: & Macromolecules \\
\hline Manuscript ID & ma-2017-016033.R1 \\
\hline Manuscript Type: & Article \\
\hline Date Submitted by the Author: & 25-Aug-2017 \\
\hline Complete List of Authors: & $\begin{array}{l}\text { Noy, Janina-Miriam; University of New South Wales, School of Chemistry } \\
\text { Friedrich, Ann-Katrin; University of New South Wales, Centre for Advanced } \\
\text { Macromolecular Design (CAMD) } \\
\text { Batten, Kyle; Curtin University, Nanochemistry Research Institute (NRI) } \\
\text { and Department of Chemistry } \\
\text { Bhebhe, Mathamsanqa; Curtin University, Nanochemistry Research } \\
\text { Institute (NRI) and Department of Chemistry } \\
\text { Busatto, Nicolas; University of Surrey, Department of Chemistry } \\
\text { Batchelor, Rhiannon; University of New South Wales, Centre for Advanced } \\
\text { Macromolecular Design (CAMD) } \\
\text { Kristanti, Ariella; University of New South Wales, Centre for Advanced } \\
\text { Macromolecular Design (CAMD) } \\
\text { Pei, Yiwen; Curtin University, Chemistry } \\
\text { Roth, Peter; University of Surrey, Department of Chemistry }\end{array}$ \\
\hline
\end{tabular}

\section{SCHOLARONE \\ Manuscripts}




\title{
Para-Fluoro Postpolymerization Chemistry of
}

\section{Poly(pentafluorobenzyl methacrylate): Modification}

\section{with Amines, Thiols, and Carbonylthiolates}

\author{
Janina-Miriam Noy, ${ }^{1}$ Ann-Katrin Friedrich, ${ }^{1}$ Kyle Batten, ${ }^{2}$ Mathamsanqa N. Bhebhe, ${ }^{2}$ Nicolas \\ Busatto, ${ }^{3}$ Rhiannon R. Batchelor, ${ }^{1}$ Ariella Kristanti, ${ }^{1}$ Yiwen Pei, ${ }^{1,2,4}$ Peter J. Roth ${ }^{1,2,3, *}$ \\ ${ }^{1}$ Centre for Advanced Macromolecular Design (CAMD), University of New South Wales, \\ Kensington, Sydney, NSW 2052, Australia; \\ ${ }^{2}$ Nanochemistry Research Institute (NRI) and Department of Chemistry, Curtin University, \\ Bentley, Perth, WA 6102, Australia; \\ ${ }^{3}$ Department of Chemistry, University of Surrey, Guildford, Surrey, GU2 7XH, United \\ Kingdom; \\ ${ }^{4}$ Department of Chemistry, University College London, London, WC1E 6BT, United Kingdom; \\ * Corresponding Author email address p.roth@surrey.ac.uk
}

\begin{abstract}
KEYWORDS: para-fluoro-thiol reaction, postpolymerization modification, tacticity by ${ }^{19} \mathrm{~F}$ NMR, zwitterionic polymers, UCST in water
\end{abstract}




\begin{abstract}
A methacrylic polymer undergoing highly efficient para-fluoro substitution reactions is presented. A series of well-defined poly(2,3,4,5,6-pentafluorobenzyl methacrylate) (pPFBMA) homopolymers with degrees of polymerization from 28 to 132 and $Ð \leq 1.29$ was prepared by the RAFT process. pPFBMA samples were atactic (with triad tacticity apparent in ${ }^{1} \mathrm{H}$ and ${ }^{19} \mathrm{~F}$ NMR spectra) and soluble in most organic solvents. pPFBMA reacted quantitatively through parafluoro substitution with a range of thiols (typically 1.1 equiv thiol, base, $\mathrm{RT},<1 \mathrm{~h}$ ) in the absence of any observed side reactions. Para-fluoro substitution with different (thio)carbonylthio reagents was possible and allowed for subsequent one-pot cleavage of dithioester pendent groups with concurrent thia-Michael side group modification. Reactions with aliphatic amines (typically 2.5 equiv amine, $50-60{ }^{\circ} \mathrm{C}$, overnight) resulted in complete substitution of the para-fluorides without any observed ester cleavage reactions. However, for primary amines, $\mathrm{H}_{2} \mathrm{NR}$, double substitution reactions yielding tertiary $\left(-\mathrm{C}_{6} \mathrm{~F}_{4}\right)_{2} \mathrm{NR}$ amine bridges were observed, which were absent with secondary amine reagents. No reactions were found for attempted modifications of pPFBMA with bromide, iodide, methanethiosulfonate, or thiourea, indicating a highly selective reactivity toward nucleophiles. The versatility of this reactive platform is demonstrated through the synthesis of a pH-responsive polymer and novel thermoresponsive polymers: an oligo(ethylene glycol)-functional species with an LCST in water and two zwitterionic polymers with UCSTs in water and aqueous salt solution ( $\mathrm{NaCl}$ concentration up to $178 \mathrm{mM})$.
\end{abstract}




\section{Introduction}

Postpolymerization modification (the introduction of chemical functionality into a pre-made reactive precursor) is a versatile synthetic pathway that provides unique access to functional materials and enables the study of structure-property relationships in series of functional daughter polymers with virtually identical degrees of polymerization. While the concept is as old and extensive as polymer science itself, ${ }^{1}$ much recent work is based on vinyl systems and the architectural control offered by the suite of reversible deactivation radical polymerization (RDRP) methods. ${ }^{2-5}$ For a reactive group to be suited for postpolymerization modification, it must (i) be compatible with polymerization conditions (or come with an easily removable protecting group) and (ii) allow for selective and efficient chemical modification, ideally under mild conditions. Commonly used chemical groups include the nucleophile-reactive epoxide, ${ }^{6,7}$ azlactone, ${ }^{8-11}$ and activated esters ${ }^{12}$ as well as unsaturated groups such as dienes and alkynes which can undergo cycloadditions and reactions with thiols. ${ }^{13,14}$

A functional group that remains underexplored in the polymer chemistry arena is the pentafluorobenzene (PFB) motif, which undergoes selective nucleophilic aromatic substitution reactions of the para-fluoride (which is the most activated having two ortho and two meta fluoride neighbors). ${ }^{15-17}$ Low molar mass PFB derivatives have been used for the synthesis of monomers ${ }^{18}$ and for polymer end group modification. ${ }^{19}$ Multifunctional PFB-functional building blocks have been condensed for the preparation of metal-containing linear polymers, ${ }^{20}$ hyperbranched polymers, ${ }^{21}$ and precision networks. ${ }^{22}$ PFB-functionalised end groups were exploited for the functionalization of polythiophenes ${ }^{23}$ and the synthesis of multi-arm copolymers. ${ }^{24}$ With regards to postpolymerization functionalization of side groups, however, the literature is, with very few exeptions, ${ }^{21,} 25-28$ limited to the modification of $2,3,4,5,6$ - 
pentafluorostyrene-based (co)polymers with amines, ${ }^{29}$ phosphite, $^{30}$ and thiols ${ }^{31-33}$ (including in water ${ }^{34}$ and on surfaces). ${ }^{35-37}$ The thiol-para-fluoro substitution reaction has been combined with (and shown to be orthogonal to) pentafluorophenyl activated esters, ${ }^{25,} 27$ radical-mediated thiolene additions, ${ }^{24,38}$ and $\mathrm{Cu}$-catalyzed azide-alkyne cycloadditions. ${ }^{39}$

Herein, the Reversible Addition-Fragmentation Chain Transfer (RAFT) ${ }^{40}$ synthesis and postpolymerization modification of poly(2,3,4,5,6-pentafluorobenzyl methacrylate), pPFBMA, a methacrylic system amenable to highly efficient para-fluoro substitution reactions, is presented for the first time. A small number of studies have described the synthesis of this polymer through anionic polymerization, ${ }^{41}$ free-radical homo- ${ }^{42}$ and copolymerization with styrene, ${ }^{43}$ and the photoinitiator-free photopolymerization ${ }^{44}$ - but not its post-modification. Acyl substitutions, key to the modification of Theato's polymeric pentafluorophenyl (PFP) esters, ${ }^{45}$ were not observed on PFB esters. Instead, pPFBMA was found to react quantitatively through para-fluoro substitution with thiols and amines, though with a certain degree of double substitution when primary amines were used. Additionally, reaction with several (thio)carbonylthio reagents enabled subsequent polymer analogous modification. The high selectivity of the para-fluoro substitution was apparent by the lack of any observed reaction with bromide, iodide, thiourea, and methanethiosulfonate nucleophiles. The versatility of this reactive scaffold is demonstrated through the preparation of novel stimulus-responsive polymers. 


\section{Experimental Section}

Instrumentation. NMR spectroscopic measurements were performed on 300, 400, or 500 $\mathrm{MHz}$ Bruker instruments in $5 \mathrm{~mm}$ NMR tubes. Residual solvent signals of $\mathrm{CHCl}_{3}\left(\delta_{\mathrm{H}}=7.26\right.$ ppm, $\left.\delta_{\mathrm{C}}=77.2 \mathrm{ppm}\right), \mathrm{DMSO}_{-} \mathrm{d}_{5}\left(\delta_{\mathrm{H}}=2.51 \mathrm{ppm}\right)$ and HDO $\left(\delta_{\mathrm{H}}=4.79 \mathrm{ppm}\right)$ were used as references. ${ }^{19} \mathrm{~F}$ NMR chemical shifts are given relative to a $\mathrm{CFCl}_{3}$ standard.

Size exclusion chromatography (SEC) in dimethylacetamide (DMAc) was performed on a Shimadzu system with four $300 \times 7.8 \mathrm{~mm}^{2}$ linear phenogel columns $\left(10^{5}, 10^{4}, 10^{3}\right.$, and $\left.500 \AA\right)$ operating at $50{ }^{\circ} \mathrm{C}$ and a flow rate of $1 \mathrm{~mL} / \mathrm{min}$. Reported values are polystyrene (PS) equivalent molar masses based on a calibration with a series of narrow molar mass distribution PS standards with molar masses ranging from 0.58 to $1,820 \mathrm{~kg} / \mathrm{mol}$.

Fourier transform infrared spectroscopy (FT-IR) was performed on a Bruker IFS 66/S instrument under attenuated total reflectance (ATR).

LCST and UCST cloud points were determined through temperature dependent optical turbidity measurements using an Avantium Crystal16 system using heating/cooling rates of 1 ${ }^{\circ} \mathrm{C} / \mathrm{min}$. Cloud points were determined at the onset of transmittance decrease during heating (LCST type) or cooling (UCST type).

Microwave heating was done in a single-mode Anton Paar Monowave 300 reactor using an infrared temperature sensor and compressed air flow for simultaneous cooling.

Differential scanning calorimetry (DSC) was done on a DSC Q1000 by TA instruments. The glass transition temperature, $T_{\mathrm{g}}$, was determined from the second heating step of a heat-coolheat cycle (rates $10^{\circ} \mathrm{C} / \mathrm{min}$ ) from the intersection of extrapolated approximately straight-line portions of the thermogram before and after the onset of heat flow change. ${ }^{46}$ 


\section{Synthesis}

General Remarks. All reagents were purchased from Sigma-Aldrich and used without purification unless stated otherwise. Azobis(isobutyronitrile) (AIBN) was recrystallized from methanol and stored in a freezer. Anhydrous $N, N$-dimethylformamide (DMF) was stored in a glove box. Acetone was dried over molecular sieves (3 $\AA$ ). The triethylammonium salt of $S$ carboxypropyl trithiocarbonic acid was prepared following a literature procedure. ${ }^{47}$

Pentafluorobenzyl methacrylate (PFBMA). Potassium carbonate (anhydrous, 17.22 g, 0.125 mol, 5 eq.) was suspended in anhydrous acetone $(160 \mathrm{~mL})$. Methacrylic acid (3.22 g, $3.17 \mathrm{~mL}$, 0.037 mol, 1.5 eq. $), 2,3,4,5,6$-pentafluorobenzyl bromide $(6.5 \mathrm{~g}, 3.76 \mathrm{~mL}, 0.025 \mathrm{~mol}, 1$ eq. $)$ and butylated hydroxytoluene (BHT, 3 small crystals) were added. The mixture was refluxed for $3 \mathrm{~h}$ and complete reaction was confirmed with TLC control (EtOAc-hexane 1:7). The mixture was filtered to remove salts and the solvent was removed under reduced pressure. The residue was dissolved in diethyl ether $(150 \mathrm{~mL})$ and extracted with water $(150 \mathrm{~mL}, \mathrm{pH} 5)$, aqueous $\mathrm{NaHCO}_{3}$ $(3 \times 150 \mathrm{~mL}, \mathrm{pH} 9)$ and water $(100 \mathrm{~mL})$ again. The organic phase was dried over magnesium sulfate, filtered through basic aluminium oxide and the solvent was removed under reduced pressure. Three batches, yields 88\%, 93\%, 95\%. ${ }^{1} \mathrm{H}$ NMR $\left(400 \mathrm{MHz}, \mathrm{CDCl}_{3}\right), \delta / \mathrm{ppm}=6.11$, $5.60\left(2 \times 1 \mathrm{H}, H_{2} \mathrm{C}=\right), 5.27\left(2 \mathrm{H}, \mathrm{t},{ }^{4} \mathrm{~J}_{\mathrm{HF}}=1.4 \mathrm{~Hz}, \mathrm{OCH}_{2}\right), 1.93\left(3 \mathrm{H}, \mathrm{CH}_{3}\right) .{ }^{13} \mathrm{C} \mathrm{NMR}(101 \mathrm{MHz}$, $\left.\mathrm{CDCl}_{3}\right), \delta / \mathrm{ppm}=166.8(C=\mathrm{O}), 147.2$ and $144.7\left(\mathrm{dm},{ }^{1} J_{\mathrm{CF}}=255 \mathrm{~Hz}, 2 \times\right.$ meta $\left.C-\mathrm{F}\right), 143.2$ and $140.7\left(\mathrm{dm},{ }^{1} J_{\mathrm{CF}}=255 \mathrm{~Hz}\right.$, para $\left.C-\mathrm{F}\right), 139.0$ and $136.5\left(\mathrm{dtd},{ }^{1} J_{\mathrm{CF}}=255 \mathrm{~Hz},{ }^{2} J_{\mathrm{CF}}=17 \mathrm{~Hz},{ }^{3} J_{\mathrm{CF}}=4\right.$ $\mathrm{Hz}, 2 \times$ ortho $C-\mathrm{F}), 135.7\left(C\left(\mathrm{CH}_{3}\right)\right), 126.9\left(\mathrm{H}_{2} C=\mathrm{C}\right), 109.7\left(\mathrm{td},{ }^{2} J_{\mathrm{CF}}=17 \mathrm{~Hz},{ }^{3} J_{\mathrm{CF}}=4 \mathrm{~Hz}\right.$, $\left.\mathrm{CH}_{2} C_{P F B}\right), 53.8\left(\mathrm{OCH}_{2}\right), 18.3\left(\mathrm{CH}_{3}\right) .{ }^{19} \mathrm{~F} \mathrm{NMR}\left(376 \mathrm{MHz}, \mathrm{CDCl}_{3}\right), \delta / \mathrm{ppm}=-141.9(\mathrm{~m}, 2 \mathrm{~F}$, ortho), -152.7 (t, 1 F, para), -161.7 (m, 2 F, meta). FT-IR v/cm ${ }^{-1}=2950,2896$ (w, C-H alkyl, 
$\mathrm{C}=\mathrm{CH}_{2}$ stretch), $1722(\mathrm{~m}-\mathrm{s}, \mathrm{C}=\mathrm{O}$ ester stretch), 1502 (s, C=C stretch), 1128 (s, C-O stretch), 1054 (s, C-F stretch). MS (ESI) $m / z(\%)=289.03(100)[\mathrm{M}+\mathrm{H}]^{+}, 290.03(10)\left[\mathrm{M}^{13 \mathrm{C}}+\mathrm{H}\right]^{+}$.

General Procedure for RAFT Polymerization. A mixture of PFBMA (varying equiv based on targeted DP), RAFT agent 2-cyano-2-propyl benzodithioate (1 equiv), AIBN stock solution (containing 0.1 equiv of AIBN in anisole), and anisole (total volume approx. 1.5-fold volume of PFBMA) were mixed in a reaction vial. A stir bar was added and the vial sealed with a septum and degassed for 30 min by purging with nitrogen through a needle with a shorter needle fitted for gas release. The vial was placed into a preheated oil bath $\left(70{ }^{\circ} \mathrm{C}\right)$ overnight (typically $15-16$ h). After cooling in an ice-water bath, a sample $(100 \mu \mathrm{L})$ was withdrawn, diluted with $\mathrm{CDCl}_{3}$ $(500 \mu \mathrm{L})$ and analysed by ${ }^{1} \mathrm{H}$ and ${ }^{19} \mathrm{~F}$ NMR spectroscopy to determine monomer conversion by comparison of the methylene group ${ }^{1} \mathrm{H}$ signals and the para $-{ }^{19} \mathrm{~F}$ NMR signals. The polymer was precipitated twice into an excess (approx. 20-30-fold in volume) of methanol and the product was collected as a pink solid by centrifugation followed by drying in vacuum at $40{ }^{\circ} \mathrm{C} .{ }^{1} \mathrm{H}$ NMR $\left(300 \mathrm{MHz}, \mathrm{CDCl}_{3}\right), \delta / \mathrm{ppm}=5.07$ and $5.03\left(2 \times \mathrm{bs}, 2 \mathrm{H}, \mathrm{OCH}_{2}\right), 2.05-1.65(\mathrm{~m}, 2 \mathrm{H}$, backbone $\left.\mathrm{CH}_{2}\right), 1.20-0.65\left(\mathrm{~m}, 3 \mathrm{H}\right.$, backbone $\mathrm{CH}_{3}$ including $1.14(5 \%) \mathrm{mm}, 0.96$ and $0.90(35 \%) \mathrm{mr}$, and 0.79 and $0.75(60 \%) r r$ triads). ${ }^{19} \mathrm{~F}$ NMR $\left(282 \mathrm{MHz}, \mathrm{CDCl}_{3}\right), \delta / \mathrm{ppm}=-141.8(5 \%),-142.1$ $(35 \%)$, and $-142.4(60 \%)(3 \mathrm{~m}, 2 \mathrm{~F}$, ortho $),-152.0(60 \%),-152.4(35 \%)$, and $-152.8(5 \%)(3 \mathrm{~m}$, $1 \mathrm{~F}$, para $),-161.5$ and $-161.7(\sim 95 \%)$ and $-162.1(\sim 5 \%)(3 \mathrm{bs}, 2 \mathrm{~F}$, meta $)$. FT-IR v/cm ${ }^{-1}=2995$, 2935 (w, C-H stretch), 1735 (m-s, C=O ester stretch), 1504 (s, C=C stretch), 1132 (s, C-O, stretch), 1052 (s, C-F, stretch). $T_{\mathrm{g}}=65^{\circ} \mathrm{C}$

Postpolymerization Modification of pPFBMA with Thiols. Generally, pPFBMA (40 mg) was dissolved in anhydrous DMF (1-2 mL) and thiol (1.1-5 equiv) and base (triethylamine or DBU, 1.05-5.1 equiv) were added. The mixture was stirred at RT $-45^{\circ} \mathrm{C}$ for $40 \mathrm{~min}-1 \mathrm{~d}$ and the 
product was precipitated into methanol or water. See main text for details. Thiophenol-modified: ${ }^{1} \mathrm{H}$ NMR $\left(300 \mathrm{MHz}, \mathrm{CDCl}_{3}\right), \delta / \mathrm{ppm}=7.29$ (bs, $\left.2 \mathrm{H}\right), 7.19$ (m, $\left.3 \mathrm{H}\right)$; Captopril-modified: ${ }^{1} \mathrm{H}$ NMR (300 MHz, DMSO-d $\left.{ }_{6}\right), \delta / p p m=4.00,3.50,2.70,1.99-1.88,1.07$; $n$-Octanethiol-modified:

${ }^{1} \mathrm{H}$ NMR $\left(300 \mathrm{MHz}, \mathrm{CDCl}_{3}\right), \delta / \mathrm{ppm}=2.97\left(\mathrm{SCH}_{2}\right), 1.60\left(\mathrm{SCH}_{2} \mathrm{CH}_{2}\right), 1.40,1.25\left(\mathrm{CH}_{2}\right), 0.86$ $\left(\mathrm{CH}_{3}\right) ; n$-Butanethiol-modified: ${ }^{1} \mathrm{H}$ NMR $\left(300 \mathrm{MHz}, \mathrm{CDCl}_{3}\right), \delta / \mathrm{ppm}=2.98\left(\mathrm{SCH}_{2}\right), 1.56$ $\left(\mathrm{SCH}_{2} \mathrm{CH}_{2}\right), 1.45\left(\mathrm{CH}_{2} \mathrm{CH}_{3}\right), 0.91\left(\mathrm{CH}_{3}\right) ; 2$-(Dimethylamino)ethanethiol-modified: ${ }^{1} \mathrm{H}$ NMR $\left(400 \mathrm{MHz}, \mathrm{CDCl}_{3}\right), \delta / \mathrm{ppm}=3.09\left(\mathrm{bt}, 2 \mathrm{H}, \mathrm{SCH}_{2}\right), 2.55\left(\mathrm{bt}, 2 \mathrm{H}, \mathrm{CH}_{2} \mathrm{~N}\right) 2.25\left(\mathrm{bs}, 6 \mathrm{H}, \mathrm{N}\left(\mathrm{CH}_{3}\right)_{2}\right)$. Backbone and $\mathrm{COOCH}_{2}$ methylene resonances as above.

\section{Quaternization of Poly[4-(2-(dimethylamino)ethylsulfanyl)-2,3,5,6-tetrafluorobenzyl} methacrylate] with 1,3-Propane Sultone. 2-(Dimethylamino)ethanethiol-modified pPFBMA (20 mg, $57 \mu \mathrm{mol}$ of repeat units, 1 equiv) was dissolved in 2,2,2-trifluoroethanol (400 $\mu \mathrm{L})$. A separately prepared solution of 1,3-propanesultone (14.8 mg, $121 \mu \mathrm{mol}, 2.1$ equiv) in 2,2,2trifluoroethanol was added and the resulting homogeneous mixture was stirred for 5 days at 40 ${ }^{\circ} \mathrm{C}$. The product was isolated by dialysis against ultrapure water and drying in vacuum. ${ }^{1} \mathrm{H}$ NMR $\left(400 \mathrm{MHz}, \mathrm{D}_{2} \mathrm{O} / \mathrm{NaBr}\right), \delta / \mathrm{ppm}=3.88\left(\mathrm{CH}_{2} \mathrm{NCH}_{2}\right), 3.49\left(\mathrm{~N}\left(\mathrm{CH}_{3}\right)_{2}\right), 3.28\left(\mathrm{SCH}_{2}, \mathrm{CH}_{2} \mathrm{SO}_{3}{ }^{-}\right), 2.50$ $\left(\mathrm{CH}_{2} \mathrm{CH}_{2} \mathrm{CH}_{2}\right)$.

\section{Quaternization of Poly[4-(2-(dimethylamino)ethylsulfanyl)-2,3,5,6-tetrafluorobenzyl} methacrylate] with 1,4-butane Sultone. 2-(Dimethylamino)ethanethiol-modified pPFBMA (20 $\mathrm{mg}, 57 \mu \mathrm{mol}$ of repeat units, 1 equiv) was dissolved in 2,2,2-trifluoroethanol $(400 \mu \mathrm{L})$. A separately prepared solution of 1,4-butane sultone $(8.8 \mu \mathrm{L}, 86 \mu \mathrm{mol}, 1.5$ equiv) in 2,2,2trifluoroethanol was added and the resulting homogeneous mixture was filled into a $2 \mathrm{~mL}$ microwaveable pressurised tube and heated to $120{ }^{\circ} \mathrm{C}$ for $15 \mathrm{~h}$ with stirring in a microwave reactor, reaching a pressure of 7 bar. Complete conversion was verified through ${ }^{19} \mathrm{~F}$ NMR 
analysis of a sample $(50 \mu \mathrm{L})$ diluted with $\mathrm{D}_{2} \mathrm{O}(550 \mu \mathrm{L})$ containing $\mathrm{NaBr}$ (approx. $10 \mathrm{mg}$ ). Excess 1,4-butanesultone phase separated from the NMR sample which did not influence the measurement. The product was isolated by dialysis against ultrapure water (residual 1,4butanesultone hydrolysed and dissolved slowly) and drying in vacuum. ${ }^{1} \mathrm{H}$ NMR (400 MHz, $\left.\mathrm{D}_{2} \mathrm{O} / \mathrm{NaBr}\right), \delta / \mathrm{ppm}=3.51\left(\mathrm{CH}_{2} \mathrm{NCH}_{2}\right), 3.22\left(\mathrm{~N}\left(\mathrm{CH}_{3}\right)_{2}\right), 3.02\left(\mathrm{SCH}_{2}, \mathrm{CH}_{2} \mathrm{SO}_{3}{ }^{-}\right), 1.98,1.89$ $\left(\mathrm{CH}_{2} \mathrm{CH}_{2} \mathrm{CH}_{2} \mathrm{CH}_{2}\right)$.

Postmodification of pPFBMA with Sodium Hydrogensulfide. A solution of pPFBMA (10 $\mathrm{mg}, 37.6 \mu \mathrm{mol}$ of repeat units, 1 equiv) in anhydrous DMF $(1.4 \mathrm{~mL})$ was purged with nitrogen for $30 \mathrm{~min}$ and sodium hydrogensulfide hydrate $(4.2 \mathrm{mg}, 75.2 \mu \mathrm{mol}, 2$ equiv) was added under reverse nitrogen flow. The mixture turned light green, green-blue, then dark blue, and green again upon stirring at RT for $30 \mathrm{~min} .{ }^{19} \mathrm{~F}$ NMR analysis of a sample $(100 \mu \mathrm{L})$ diluted with $\mathrm{CDCl}_{3}$ $(500 \mu \mathrm{L})$ confirmed complete reaction. ${ }^{19} \mathrm{~F}$ NMR $\left(282 \mathrm{MHz}, \mathrm{CDCl}_{3}\right), \delta / \mathrm{ppm}=-139.3(\mathrm{~s}, 2 \mathrm{~F})$ and -139.6 (s, 2 F), no residual starting material signals. Upon purification by dialysis against methanol, the polymer crosslinked.

Triethylammonium $\boldsymbol{p}$-Fluorodithiobenzoate. The (unstable) acid derivative was prepared from 4-fluorophenylmagnesium bromide solution (1 M in THF) and carbon disulfide according to a literature procedure, ${ }^{48}$ followed by addition of triethylamine and drying in vacuum.

\section{Postpolymerization Modification of pPFBMA with Dithiobenzoate, Followed by} Aminolysis and Thiol-ene Modification. pPFBMA $(13.1 \mathrm{~kg} / \mathrm{mol}, \mathrm{Ð}=1.20,11.7 \mathrm{mg}, 44 \mu \mathrm{mol}$ of repeat units, 1 equiv) was dissolved in DMF $(1.4 \mathrm{~mL})$ and triethylammonium $p$ fluorodithiobenzoate $(20.8 \mathrm{mg}, 76 \mu \mathrm{mol}, 1.7$ equiv) and triethylamine (17 $\mu \mathrm{L}, 122 \mu \mathrm{mol}, 2.8$ equiv) were added. The pink solution was stirred at $65{ }^{\circ} \mathrm{C}$ for $24 \mathrm{~h} .{ }^{19} \mathrm{~F}$ NMR analysis of a sample $(250 \mu \mathrm{L})$ diluted with $\mathrm{CDCl}_{3}(350 \mu \mathrm{L})$ confirmed absence of starting material signals. 
The mixture was cooled to RT and butyl acrylate (27 $\mu \mathrm{L}, 189 \mu \mathrm{mol}, 4.3$ equiv) and tertbutylamine ( $60 \mu \mathrm{L}, 569 \mu \mathrm{mol}, 12.9$ equiv) were added and the mixture stirred overnight at RT. The product was precipitated into diethyl ether-hexane $(4: 1)$ and dried in vacuum. ${ }^{19} \mathrm{~F}$ NMR $\left(282 \mathrm{MHz}, \mathrm{DMSO}-\mathrm{d}_{6}\right), \delta / \mathrm{ppm}=-134.0(\mathrm{bs}, 2 \mathrm{~F}),-141.6(\mathrm{bs}, 2 \mathrm{~F}), \mathrm{SEC} 44.1 \mathrm{mg} / \mathrm{mol}, \mathrm{D}=1.56$, bimodal.

Postpolymerization Modification of pPFBMA with Amines. Generally, pPFBMA (40 mg, $0.15 \mathrm{mmol}$ of repeat units, 1 equiv) was dissolved in anhydrous DMF (1 mL) and butyl acrylate (to scavenge thiols release through RAFT end group aminolysis, $5 \mu \mathrm{L})^{49}$ and amine (butylamine, pentylamine, cyclohexylamine, piperidine, 3-(dimethylamino)propylamine, aniline, 4benzylpiperidine, 1-(2-hydroxyethyl)piperazine, di(ethylene glycol) methyl ether amine (2EG), tri(ethylene glycol) methyl ether amine (3EG), PEG $_{350}$ methyl ether amine, 2.5 equiv) was added. The mixture was stirred at 50 or $60{ }^{\circ} \mathrm{C}$. Conversion was monitored by withdrawing samples $(50 \mu \mathrm{L})$ diluting with $\mathrm{CDCl}_{3}(600 \mu \mathrm{L})$ and analysing by ${ }^{19} \mathrm{~F}$ NMR spectroscopy. Complete disappearance of starting material signals was achieved in 10-144 h (see details in main text). In cases where the ammonium hydrofluoride precipitated it was removed by filtration. Products were isolated by precipitation into methanol or dialysis (regenerated cellulose, MWCO $3500 \mathrm{Da}$ ) against methanol or water-ethanol 1:1. Butylamine-modified: ${ }^{1} \mathrm{H}$ NMR (300 MHz, $\left.\mathrm{CDCl}_{3}\right), \delta / \mathrm{ppm}=3.38,1.57,1.40,0.93$; Pentylamine-modified: ${ }^{1} \mathrm{H}$ NMR $(300$ $\left.\mathrm{MHz}, \mathrm{CDCl}_{3}\right), \delta / \mathrm{ppm}=3.37,1.59,1.48,1.31,0.89 ;$ Cyclohexylamine-modified: ${ }^{1} \mathrm{H}$ NMR $(300$ $\left.\mathrm{MHz}, \mathrm{CDCl}_{3}\right), \delta / \mathrm{ppm}=3.50(\mathrm{CHNH}) 2.05-0.70\left(\mathrm{CH}_{2}\right) ;$ 3-(Dimethylamino)propylaminemodified: ${ }^{1} \mathrm{H}$ NMR $\left(300 \mathrm{MHz}, \mathrm{CDCl}_{3}\right), \delta / \mathrm{ppm}=3.52\left(\mathrm{NHCH}_{2}\right), 2.55\left(\mathrm{CH}_{2} \mathrm{~N}\right), 2.32\left(\mathrm{~N}\left(\mathrm{CH}_{3}\right)_{2}\right)$, $1.83\left(\mathrm{CH}_{2} \mathrm{CH}_{2} \mathrm{CH}_{2}\right)$; Piperidine-modified: ${ }^{1} \mathrm{H}$ NMR $\left(300 \mathrm{MHz}, \mathrm{CDCl}_{3}\right), \delta / \mathrm{ppm}=3.21$ $\left(\mathrm{CH}_{2} \mathrm{~N}(\mathrm{R}) \mathrm{CH}_{2}\right), \quad 1.64,1.61\left(\mathrm{CH}_{2} \mathrm{CH}_{2} \mathrm{CH}_{2}\right) ; 2 \mathrm{EG} / 3 \mathrm{EG} / \mathrm{PEG}_{350}$-modified: ${ }^{1} \mathrm{H} \mathrm{NMR}\left(\mathrm{CDCl}_{3}-\right.$ 
$\left.\mathrm{CD}_{3} \mathrm{OD} 10: 1,400 \mathrm{MHz}\right) \delta / \mathrm{ppm}=3.55,3.45\left(\mathrm{OCH}_{2}\right), 3.29\left(\mathrm{OCH}_{3}\right), 2.88\left(\mathrm{NHCH}_{2}\right) .4-$ Benzylpiperidine-modified: ${ }^{1} \mathrm{H}$ NMR (400 MHz, $\mathrm{CDCl}_{3}$ ), $\delta / \mathrm{ppm}=7.24,7.13(P h), 3.31,3.02$

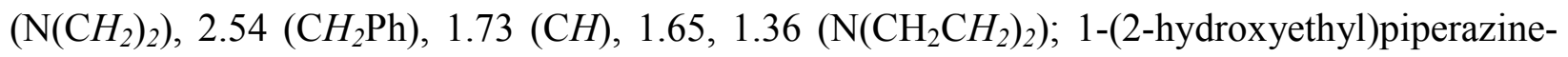
modified: ${ }^{1} \mathrm{H}$ NMR $\left(400 \mathrm{MHz}, \mathrm{CDCl}_{3}\right), \delta / \mathrm{ppm}=3.67\left(\mathrm{CH}_{2} \mathrm{OH}\right), 3.34\left(\mathrm{Ar}-\mathrm{NCH}_{2} \mathrm{CH}_{2}\right), 2.64$ $\left(\mathrm{N}\left(\mathrm{CH}_{2}\right)_{3}\right)$. Backbone and $\mathrm{COOCH}_{2}$ methylene resonances as above; for SEC and ${ }^{19} \mathrm{~F}$ NMR data see main text. 


\section{Results and Discussion}

\section{Synthesis of Monomers and Polymers}

2,3,4,5,6-Pentafluorobenzyl acrylate (PFBA) and 2,3,4,5,6-pentafluorobenzyl methacrylate (PFBMA) were prepared in high yields from (meth)acrylic acid and 2,3,4,5,6-pentafluorobenzyl bromide as confirmed by ${ }^{1} \mathrm{H},{ }^{13} \mathrm{C}$, and ${ }^{19} \mathrm{~F}$ NMR spectroscopy, ESI mass spectrometry and FT-IR spectroscopy, see Scheme 1A and Figures S1-S8 in the supporting information. While the ${ }^{19} \mathrm{~F}$ NMR signals of the bromide starting material and the (meth)acrylate products did not differ strongly (Table 1), the benzylic methylene group ${ }^{1} \mathrm{H}$ NMR signal shifted from $\delta / \mathrm{ppm}=4.49$ (for the bromide) to $\delta / \mathrm{ppm}=5.27$ and appeared as a triplet with a ${ }^{4} J_{\mathrm{HF}}$ coupling constant of $1.4-1.5$ Hz.

Scheme 1. Synthesis of the reactive monomers 2,3,4,5,6-pentafluorobenzyl acrylate and 2,3,4,5,6-pentafluorobenzyl methacrylate (A) and RAFT polymerization (B)
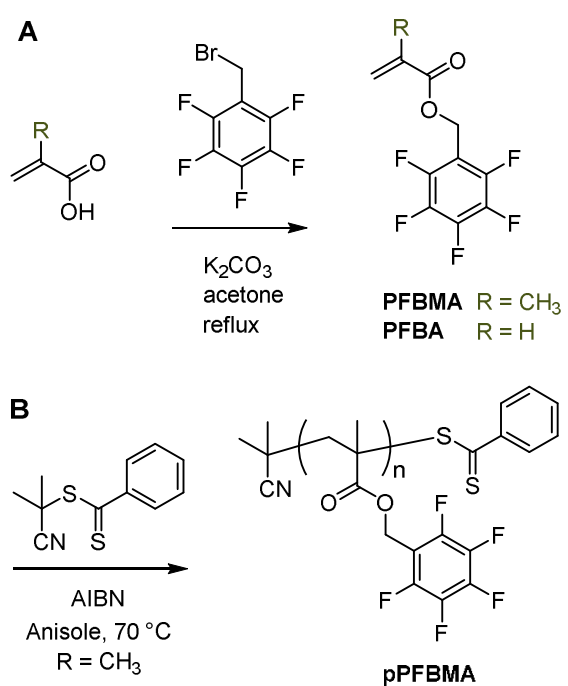
Table 1. Summary of measured ${ }^{19} \mathrm{~F}$ NMR chemical shifts in $\mathrm{CDCl}_{3}$ of 2,3,4,5,6pentafluorobenzyl derivatives (sections 1,2) and 2,3,5,6-tetrafluorobenzyl derivatives after substitution of the para-F with sulfur- and nitrogen-based nucleophiles (section 3).

\begin{tabular}{lccc}
$\begin{array}{l}\text { Functional group } \\
\text { 1. Small 2,3,4,5,6-Pentafluorobenzyl-functional }\end{array}$ & $\begin{array}{c}\boldsymbol{\delta}_{\mathrm{F}} / \mathbf{p p m} \text { (ortho to } \\
\text { benzylic) }\end{array}$ & $\begin{array}{c}\boldsymbol{\delta}_{\mathrm{F}} / \mathbf{p p m} \text { (meta to } \\
\text { benzylic) }\end{array}$ & $\begin{array}{c}\boldsymbol{\delta}_{\mathrm{F}} / \mathbf{p p m} \text { (para } \mathrm{F}_{5} \mathrm{C}_{6}-\mathrm{CH}_{2}-\mathrm{R},-\mathrm{R}= \\
\text { to benzylic) }\end{array}$ \\
\hline $\begin{array}{l}\text { Bromide }(-\mathrm{Br}) \\
\text { Hydrogen }(-\mathrm{H})\end{array}$ & -142.2 & -161.2 & -152.8 \\
Acrylate $\left(-\mathrm{OOC}-\mathrm{CH}=\mathrm{CH}_{2}\right)$ & -143.3 & -163.6 & -158.9 \\
Methacrylate $\left(-\mathrm{OOC}-\mathrm{C}\left(\mathrm{CH}_{3}\right)=\mathrm{CH}_{2}\right)$ & -141.9 & -161.8 & -152.7 \\
\end{tabular}

2. Poly(2,3,4,5,6-pentafluorobenzyl methacrylate)

\begin{tabular}{llll}
\hline pPFBMA $^{\mathrm{a}}$ & -142.4 & -161.6 & -152.0
\end{tabular}

3. para-Substituted Polymers, $\mathrm{R}-\mathrm{F}_{4} \mathrm{C}_{6}-\mathrm{CH}_{2} \mathrm{O}--, \mathrm{R}-=$

\begin{tabular}{|c|c|c|}
\hline Alkylthio (R'S-, 7 examples) ${ }^{b}$ & -141.6 to -142.7 & -133.8 to -134.6 \\
\hline $\begin{array}{l}\text { Carbonylthio }\left(\mathrm{R}^{\prime} \mathrm{C}(=\mathrm{X}) \mathrm{S} \text {-; thioacetate, dithioester, }\right. \\
\text { trithiocarbonate) }\end{array}$ & -141.0 to -142.0 & -133.9 to -134.3 \\
\hline Phenylthio (PhS—) & -141.7 & -132.5 \\
\hline Sodium sulfido (NaS- $)$ & -149.7 & -139.4 \\
\hline Alkylamino (R'HN-, 7 examples) & -145.6 to -146.5 & -160.6 to -161.8 \\
\hline $\operatorname{Amino}\left(\mathrm{H}_{2} \mathrm{~N}-\right)^{\mathrm{c}}$ & -145.2 & -162.8 \\
\hline Dialkylamino $\left(\mathrm{R}_{2} \mathrm{~N}-, 10\right.$ examples $)$ & -144.7 to -146.2 & -151.1 to -152.3 \\
\hline \multicolumn{3}{|c|}{$\begin{array}{l}\text { a shift of major signal where tacticity splitting occurs; }{ }^{\mathrm{b}} \text { There is disagreement in the literature } \\
\text { on the assignment of }{ }^{19} \mathrm{~F} \text { NMR resonances of para thiol-substituted } 2,3,5,6 \text {-tetrafluorobenzyl } \\
\text { derivatives. Assignments in this table are based on the measurement and interpretation of }{ }^{1} \mathrm{H}- \\
\text { decoupled and non- }{ }^{1} \mathrm{H}-\mathrm{dec} \text { - } \\
\text { para-fluoro substitution with thiophenol. The ortho-fluorines of these low molar mass species } \\
{ }^{19} \mathrm{~F} \text { NMR spectra of } 2,3,4,5,6 \text {-pentafluorotoluene and after } \\
\text { can be identified by their coupling to the toluic } \mathrm{CH}_{3} \text { group, see Figure S9; }{ }^{\mathrm{c}} \mathrm{J} \text {.-M. Noy, P. J. Roth } \\
\text { et al. unpublished work }\end{array}$} \\
\hline
\end{tabular}


After washing and filtration over basic aluminum oxide, PFBMA was of sufficient purity for RAFT polymerization without the need for chromatography or distillation. Six samples of poly(PFBMA), pPFBMA, with degrees of polymerization ranging from 28 to 132 and narrow, monomodal molar mass distributions were prepared using the RAFT process, see Scheme 1B, Table 2, and Figure 1A. The PFB functional groups were stable during polymerization with no observed evidence of decomposition or adverse effects on the polymerization. A slight difference in ${ }^{19} \mathrm{~F}$ chemical shifts between monomers and polymers enabled simple estimations of monomer conversions using ${ }^{19} \mathrm{~F}$ NMR spectroscopy before polymer isolation. All samples of pPFBMA were powdery solids with a measured glass transition temperature of $T_{\mathrm{g}}=65^{\circ} \mathrm{C}$, higher than that of the non-fluorinated analogue poly(benzyl methacrylate) $\left(T_{\mathrm{g}}=54{ }^{\circ} \mathrm{C}\right),{ }^{50}$ but lower than that of the reactive styrenic counterpart poly $(2,3,4,5,6$-pentafluorostyrene $)\left(T_{\mathrm{g}}=95{ }^{\circ} \mathrm{C}\right) .{ }^{51} \mathrm{pPFBMA}$ was found to be soluble in chloroform, $N, N$-dimethylformamide, $N, N$-dimethylacetamide, dimethyl sulfoxide, acetonitrile, anisole, acetone, tetrahydrofuran, diethyl ether, pyridine, and 2,2,2trifluoroethanol, but insoluble in water, methanol, and hexane. As to be expected from radical polymerization, pPFBMA samples were atactic with a measured triad tacticity of $0.05 \mathrm{~mm}: 0.35$ $m r: 0.60 \mathrm{rr}$ determined by ${ }^{1} \mathrm{H}$ NMR spectroscopic analysis of the backbone methyl group resonances (Figure S10). Interestingly, all three ${ }^{19} \mathrm{~F}$ NMR signals of pPFBMA showed a splitting with a similar integral ratio (see experimental section and Figure S11) suggesting that all fluorine atoms are affected by (and can be analyzed to determine) tacticity. ${ }^{19} \mathrm{~F}$ NMR spectroscopy has been shown to be a powerful tool in determining tacticity. ${ }^{52-54}$ Notably, however, for many reported cases the decisive fluorine atoms were directly attached to the backbone. ${ }^{55-57}$ The ${ }^{1} \mathrm{H}$ NMR signal of the methylene side group ( $\left.\mathrm{COO}-\mathrm{CH}_{2}-\mathrm{PFB}\right)$ roughly reflected a similar splitting 
with the main peaks $(\delta / \mathrm{ppm}=5.07,5.03)$ showing an approximate $60: 35$ integration ratio and the expected $5 \%$ component apparent as a shoulder around $\delta=5.16 \mathrm{ppm}$.

Table 2. List of prepared pPFBMA samples. ${ }^{\text {a }}$

\begin{tabular}{cccccc} 
Code & Target DP & $\begin{array}{c}\text { Conversion }^{\mathbf{b}} \\
\mathbf{( \% )}\end{array}$ & $\mathbf{D P}^{\mathbf{N M R}, \mathbf{b}}$ & $\begin{array}{c}\boldsymbol{M}_{\mathbf{n}}^{\text {SEC }} \\
(\mathbf{k g} / \mathbf{m o l})\end{array}$ & $\boldsymbol{\Xi}^{\text {SEC }}$ \\
\hline pPFBMA $_{28}$ & 38 & 74 & 28 & 8.6 & 1.15 \\
pPFBMA $_{36}$ & 41 & 87 & 36 & 10.3 & 1.15 \\
pPFBMA $_{63}$ & 68 & 92 & 63 & 13.1 & 1.20 \\
pPFBMA $_{70}$ & 100 & $70^{c}$ & 70 & 16.3 & 1.14 \\
pPFBMA $_{98}$ & 100 & 98 & 98 & 15.0 & 1.14 \\
pPFBMA $_{132}$ & 197 & 67 & 132 & 19.8 & 1.29
\end{tabular}

a RAFT polymerizations were done using chain transfer agent 2-cyano-2-propyl benzodithioate, solvent anisole, and initiator AIBN at $70{ }^{\circ} \mathrm{C}$ overnight; ${ }^{b}$ determined by ${ }^{1} \mathrm{H}$ and ${ }^{19}$ F NMR spectroscopy before purification; ${ }^{\mathrm{c}}$ reaction time $8 \mathrm{~h}$ 

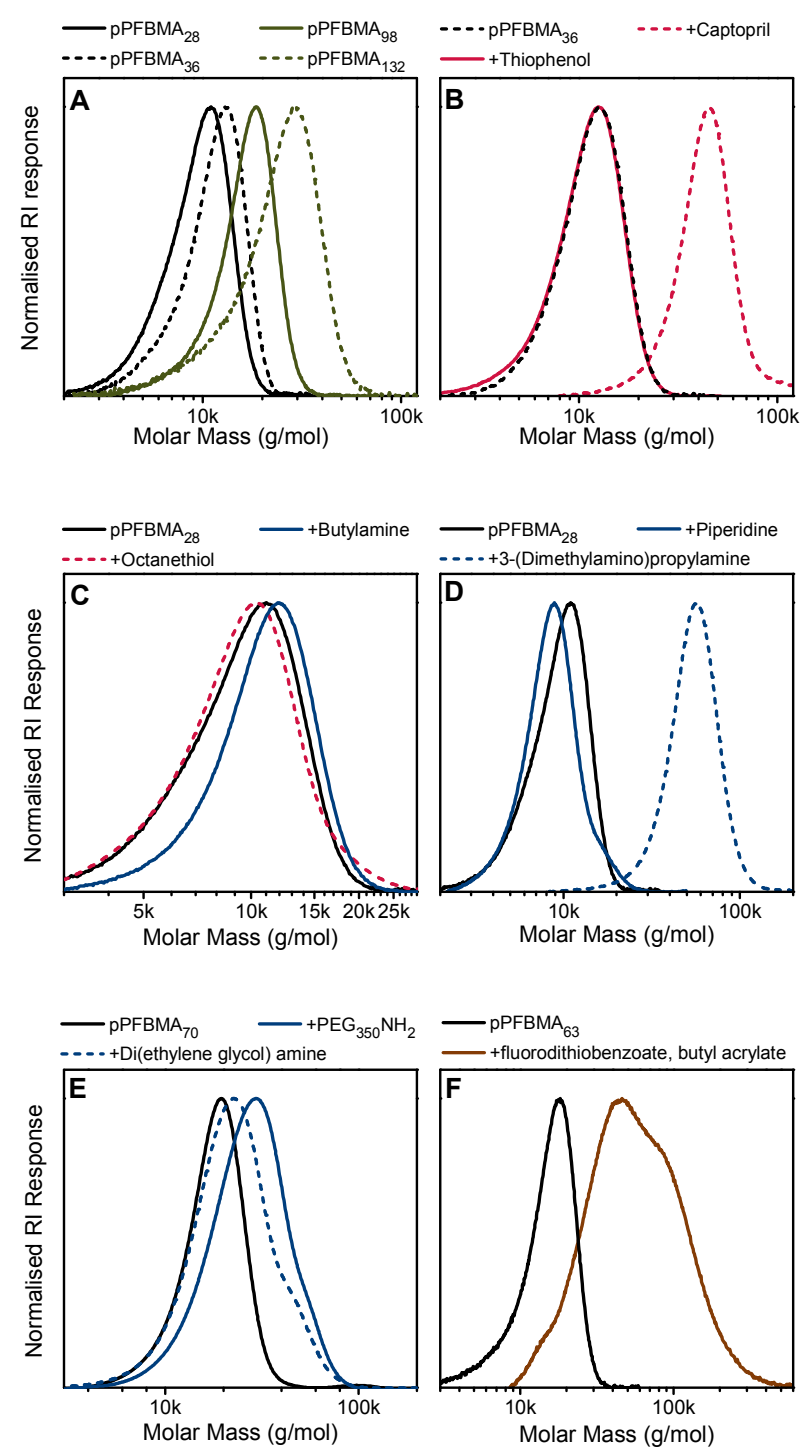

Figure 1. SEC traces of reactive pPFBMA species (A), and after postpolymerization para-fluoro substitution with thiols $(\mathbf{B}, \mathbf{C})$, amines $(\mathbf{C}, \mathbf{D}, \mathbf{E})$ and double modification with dithiobenzoate followed by aminolysis and thiol-ene modification $(\mathbf{F}) . \mathrm{x}$-Axes are PS-equivalent molar masses in $N, N$-dimethylacetamide at $50^{\circ} \mathrm{C}$. 


\section{Polymer Modification: Thiols}

With a series of well-defined pPFBMA polymers in hand, their reactivity toward a range of sulfur- and nitrogen-based nucleophiles was assessed. Samples of pPFBMA were first reacted with thiophenol in the presence of triethylamine and five different primary aliphatic thiols, including hydrophilic and hydrophobic species and the drug captopril, using 1,8diazabicyclo[5.4.0]undec-7-ene (DBU) as base, ${ }^{25}$ see Scheme 2 and Table 3. Conversions were monitored by withdrawing reaction samples, diluting with $\mathrm{CDCl}_{3}$ and measuring ${ }^{19} \mathrm{~F}$ NMR spectroscopy. Reactions were continued until all ${ }^{19} \mathrm{~F}$ NMR signals associated with starting material had disappeared (40 min-2 h). Isolated products were characterized by ${ }^{1} \mathrm{H}$ and ${ }^{19} \mathrm{~F}$ NMR spectroscopy, FT-IR spectroscopy and SEC.

Scheme 2. para-Fluoro Postpolymerization Modification of pPFBMA with thiols

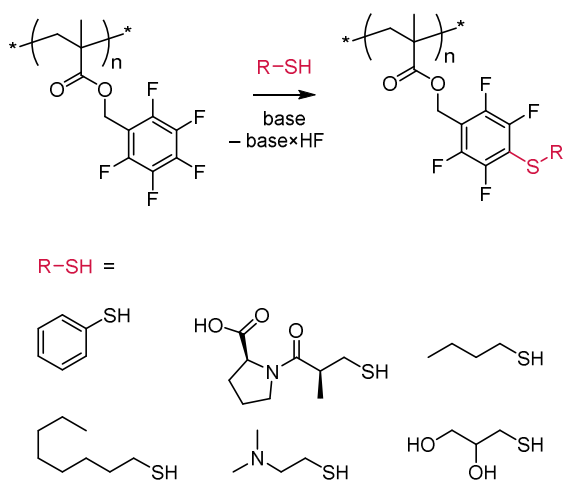


Table 3. Overview of reaction conditions and SEC results for postpolymerization modifications of pPFBMA with thiols. ${ }^{\text {a }}$

\begin{tabular}{|c|c|c|c|c|c|c|c|c|c|}
\hline \multirow[t]{2}{*}{ Entry } & \multirow[t]{2}{*}{ Thiol } & \multirow[t]{2}{*}{$\begin{array}{l}\text { Thiol } \\
\text { equiv }\end{array}$} & \multirow[t]{2}{*}{$\begin{array}{l}\text { Base, } \\
\text { equiv }\end{array}$} & \multirow[t]{2}{*}{$\begin{array}{l}\text { Temp. } \\
\left({ }^{\circ} \mathbf{C}\right)\end{array}$} & \multirow[t]{2}{*}{$\begin{array}{c}\text { Reaction } \\
\text { time (min) }\end{array}$} & \multicolumn{2}{|c|}{ before modification } & \multicolumn{2}{|c|}{$\begin{array}{c}\text { after } \\
\text { modification }\end{array}$} \\
\hline & & & & & & $\begin{array}{c}M_{\mathrm{n}}^{\mathrm{SEC}} \\
(\mathbf{k g} / \mathbf{m o l})\end{array}$ & $\overline{\boldsymbol{D}^{\mathrm{SEC}}}$ & $\begin{array}{c}M_{\mathrm{n}}^{\mathrm{SEC}} \\
(\mathrm{kg} / \mathrm{mol})\end{array}$ & $\overline{\boldsymbol{D}^{\mathrm{SEC}}}$ \\
\hline 1 & Thiophenol $^{\mathrm{c}}$ & 1.1 & $\mathrm{Et}_{3} \mathrm{~N}, 1.05$ & 45 & 60 & 10.5 & 1.15 & 10.3 & 1.16 \\
\hline 2 & Captopril $^{\mathrm{c}}$ & 1.1 & DBU, $2.1^{\mathrm{d}}$ & 25 & 40 & 10.5 & 1.15 & 39.3 & 1.15 \\
\hline 3 & Butane-1-thiol ${ }^{\mathrm{c}}$ & 1.1 & DBU, 1.05 & 25 & 40 & 8.6 & 1.15 & 10.3 & 1.18 \\
\hline 4 & Octane-1-thiol ${ }^{\mathrm{c}}$ & 1.1 & DBU, 1.05 & 25 & 40 & 8.6 & 1.15 & 8.5 & 1.16 \\
\hline 5 & $\begin{array}{l}\text { 2- } \\
\text { (Dimethylamino)ethanethiol } \\
\text { hydrochloride }^{\mathrm{e}}\end{array}$ & $5.0^{\mathrm{f}}$ & DBU, 5.1 & 25 & 90 & 16.3 & 1.14 & n.d. & n.d. \\
\hline 6 & 1-Thioglycerol ${ }^{8}$ & $1.5^{\mathrm{f}}$ & DBU, 1.4 & 25 & 120 & 16.3 & 1.14 & n.d. & n.d. \\
\hline
\end{tabular}

a In all cases, anhydrous $N, N$-dimethylformamide was used as solvent and quantitative conversions were confirmed by ${ }^{19} \mathrm{~F}$ NMR spectroscopy; ${ }^{\mathrm{b}}$ with regards to 1 equiv of PFBMA repeat units; ${ }^{\mathrm{c}}$ the product was purified by precipitation into methanol; ${ }^{\mathrm{d}}$ additional base was used due to the carboxylic acid group on captopril; ${ }^{\mathrm{e}}$ in the presence of DBU the tertiary aminefunctional polymer is isolated (as shown in Scheme 2); the product was purified by precipitation into water; f incomplete reaction when lower amount was used; ${ }^{\mathrm{g}}$ the product was purified by dialysis against methanol

In all cases, selective substitution of the para-fluoride was found with no observed evidence of ester cleavage or substitution of ortho- or meta-fluorides. ${ }^{19} \mathrm{~F}$ NMR spectra of pPFBMA and after modification with thiophenol and a representative aliphatic thiol are shown in Figure 2A-C. Quantitative substitution was apparent by the disappearance of the $\operatorname{para}^{19} \mathrm{~F}$ signal and a downfield shift of approx. $28 \mathrm{ppm}$ ( $c f$. Table 1) of the meta fluorides, the neighbors of the functionalized position. Before purification, the replaced (former para) fluoride appeared as broad signal between -120 and -165 ppm in ${ }^{19} \mathrm{~F}$ NMR spectra, usually with a lower-thanexpected integral. Addition of excess of $\mathrm{DBU}$ to $\mathrm{NMR}$ samples (in $\mathrm{CDCl}_{3}$ ) resulted in a sharp singlet at $\delta / \mathrm{ppm}=-123.2$ associated with the DBU hydrofluoride salt. After purification, ${ }^{19} \mathrm{~F}$ 
NMR signals associated with the replaced para-fluoride disappeared. ${ }^{1} \mathrm{H}$ NMR spectroscopy confirmed the quantitative formation of functional thioether derivatives, including through the appearance of a resonance associated with $\mathrm{R}-\mathrm{CH}_{2}-\mathrm{SC}_{6} \mathrm{~F}_{4}$ methylene groups (for $\mathrm{R}=$ alkyl, $\delta / \mathrm{ppm}\left(\mathrm{R}-\mathrm{CH}_{2}-\mathrm{SC}_{6} \mathrm{~F}_{4}\right)=2.98(\mathrm{bt})$, compared to $\delta / \mathrm{ppm}\left(\mathrm{R}-\mathrm{CH}_{2}-\mathrm{SH}\right)=2.54$ (q) for the respective thiol reagent). ${ }^{1} \mathrm{H}$ NMR spectroscopic analysis also indicated that excess reagent, base, and any other small molecules had been removed during purification, Figure 3A-C. FT-IR spectra of pPFBMA and after modification with 2-(dimethylamino)ethanethiol are shown in Figure 4. While the carbonyl $\mathrm{C}=\mathrm{O}$ stretching band $\left(v=1735 \mathrm{~cm}^{-1}\right)$ was not significantly affected through the thiol-para-F substitution (suggesting, as desired, the absence of acyl substitution reactions), a red-shift of the $\mathrm{C}=\mathrm{C}$ aromatic vibrations from $v\left(\mathrm{C}_{6} \mathrm{~F}_{5}\right)=1504 \mathrm{~cm}^{-1}$ to $v\left(\mathrm{C}_{6} \mathrm{~F}_{4} \mathrm{SR}\right)=$ $1472 \mathrm{~cm}^{-1}$ was observed in agreement with the change in the aromatic substitution pattern.

SEC of thiol-modified samples revealed molar mass distributions and dispersities very similar to those of the respective reactive starting materials (Table 3, Figure 1BC), as to be expected for the post-polymerization modification of side groups in the absence of side reactions. Apparent molar masses, however, were found to decrease slightly or increase (most significantly for the reaction with captopril, Table 3 Entry 2). It is stressed that SEC separates polymers by hydrodynamic size (not molar mass). The observed changes in measured PS-equivalent molar masses thus indicated a compaction or expansion of the modified polymer chains under the measurement conditions, in agreement with their chemical modification. 
Figure 2. ${ }^{19} \mathrm{~F}$ NMR spectra of pPFBMA (A, $\left.500 \mathrm{MHz}\right)$ and after para-fluoro substitution reaction with thiols $(\mathbf{B}$ and $\mathbf{C}, 300 \mathrm{MHz}$ ), sodium hydrogen sulfide $(\mathbf{D}, 300 \mathrm{MHz}$ ), primary amines $(\mathbf{E}, \mathrm{n}-\mathrm{Bu}=n$-butyl, $300 \mathrm{MHz}$, and $\mathbf{F}, 3 \mathrm{EG}=$ tri(ethylene glycol $)$ methyl ether amine, 400 $\mathrm{MHz}$ ) and piperidine (F, $300 \mathrm{MHz})$ 


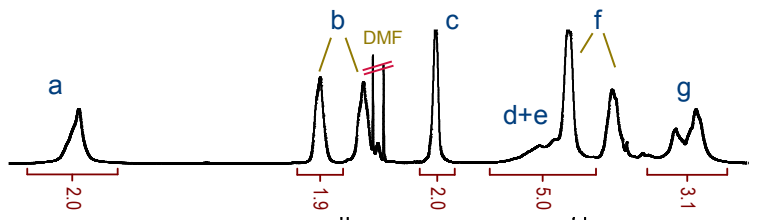

(D)
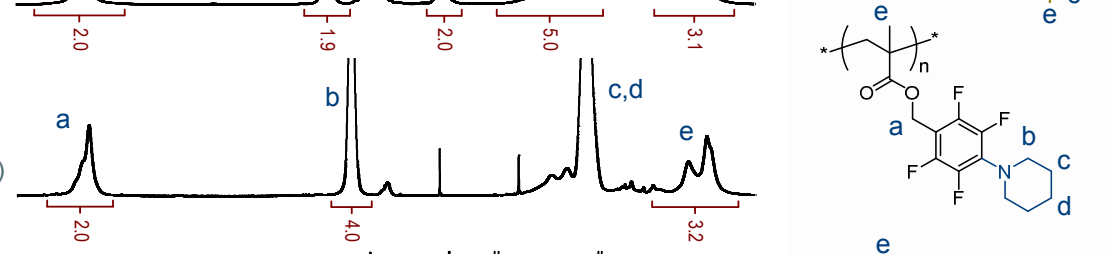

(C)
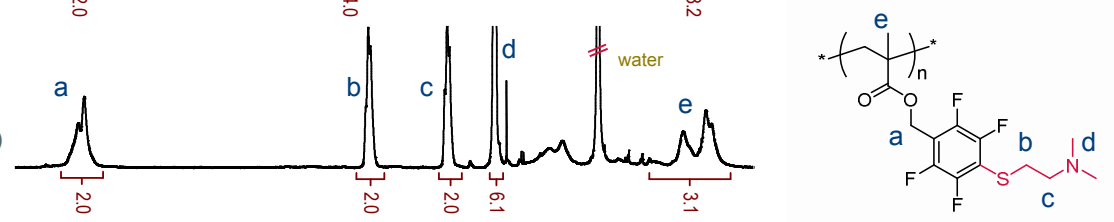

(B)
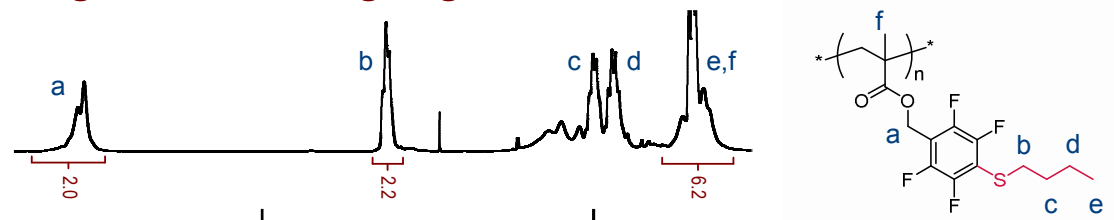

(A)
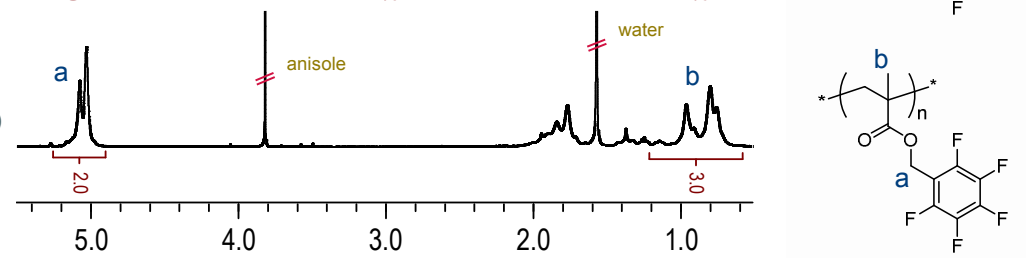

Figure 3. ${ }^{1} \mathrm{H}$ NMR spectra in $\mathrm{CDCl}_{3}$ of pPFBMA (A, $\left.500 \mathrm{MHz}\right)$, and after modification with butane-1-thiol (B, $300 \mathrm{MHz}$ ), 2-(dimethylamino)ethanethiol hydrochloride (in the presence of DBU) (C, $400 \mathrm{MHz})$, piperidine (D, $300 \mathrm{MHz}$ ), and 4-benzylpiperidine (E, $400 \mathrm{MHz}$ ) with relevant signals integrated and assigned. 


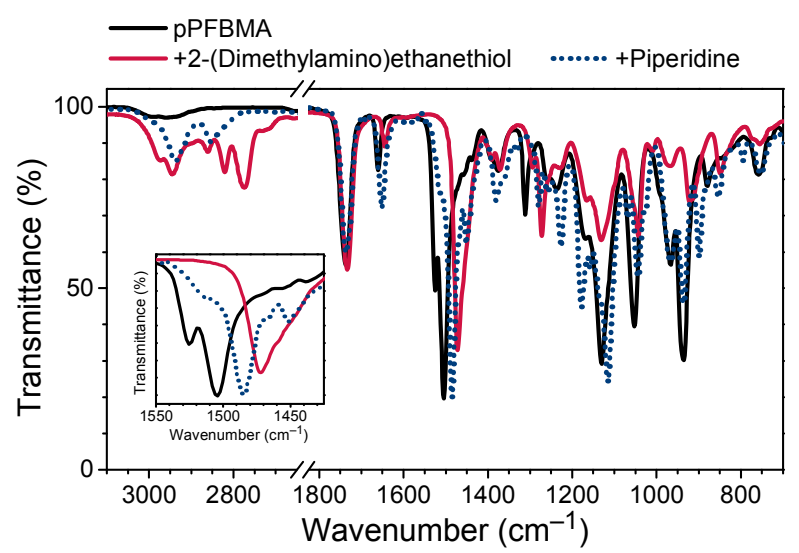

Figure 4. FT-IR spectra of pPFBMA (black) and after modification with 2(dimethylamino)ethanethiol (red) and piperidine (dotted) with the shift of the aromatic $\mathrm{C}=\mathrm{C}$ stretching vibration inset.

\section{Polymer Modification: Other sulfur-based nucleophiles}

Given the observed quantitative modification with thiols under mild conditions, modification of pPFBMA with a range of other sulfur-based nucleophiles was attempted, Scheme 3. A desired synthetic strategy was the introduction of a nucleophile that would allow for subsequent release of a tetrafluorophenylthiol $\left(\mathrm{RC}_{6} \mathrm{~F}_{5} \rightarrow \mathrm{RC}_{6} \mathrm{~F}_{4}-\mathrm{SR}^{\prime} \rightarrow \mathrm{RC}_{6} \mathrm{~F}_{4}-\mathrm{SH}\right)$, to set the stage for a range of efficient thiol-X click chemistries ${ }^{58}$ for further modification. To this end, reaction was first attempted using sodium methanethiosulfonate in a synthetic route that was also envisaged to provide access to functional non-symmetrical disulfides $\left(\mathrm{RC}_{6} \mathrm{~F}_{5} \rightarrow \mathrm{RC}_{6} \mathrm{~F}_{4}-\mathrm{SSO}_{2} \mathrm{R}^{\prime} \rightarrow \mathrm{RC}_{6} \mathrm{~F}_{4}-\right.$ SS-R" $)^{59}$ (Scheme 3A) with potential for drug releasing applications. ${ }^{60}$ However, under all investigated reaction conditions (solvents $N, N$-dimethylformamide, dimethylsulfoxide, pyridine; without base, with DBU, with triethylamine; temperatures from RT to $80{ }^{\circ} \mathrm{C}$ ), no reaction was observed. When reactions were heated to $130{ }^{\circ} \mathrm{C}$ (or $90{ }^{\circ} \mathrm{C}$ in the presence of DBU), ${ }^{19} \mathrm{~F}$ NMR analysis showed multiple sharp signals suggesting the formation of small fluorinated molecules 
through acyl substitution (pentafluorobenzyl alcohol side product) or through nucleophilic substitution at the benzylic position (polymeric carboxylate leaving group and formation of substituted pentafluorobenzyl products).

Scheme 3. Reaction of pPFBMA with the sulfur-based nucleophiles sodium methanethiosulfonate (A), sodium hydrogensulfide (B), potassium thioacetate (C), $S$ carboxypropyl trithiocarbonic acid, bis(triethylammonium) salt (D) and triethylammonium 4fluorodithiobenzoate (E) followed by aminolysis and thia-Michael modification with butyl acrylate $(\mathbf{F})$

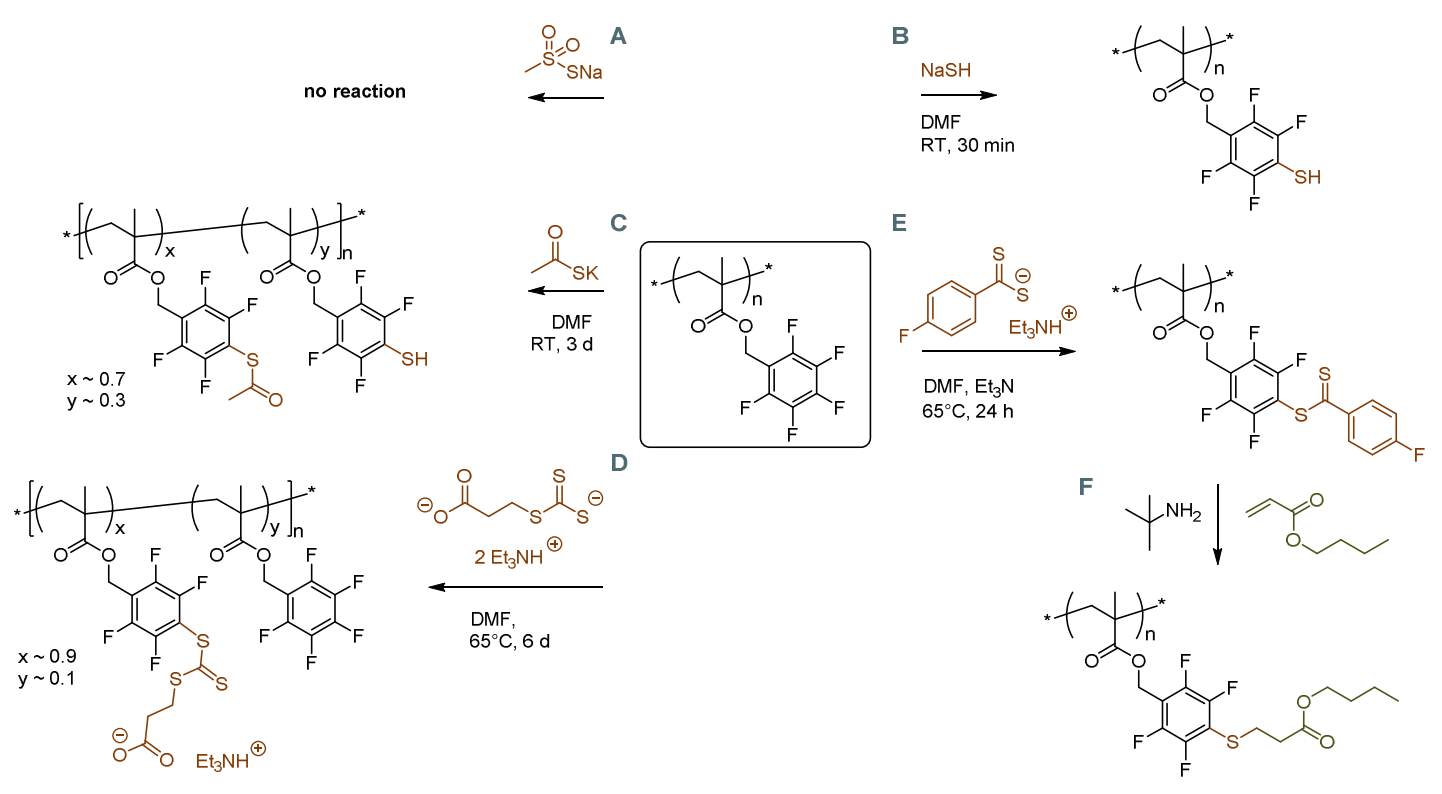


Reaction of pPFBMA with sodium hydrogensulfide in the absence of base was successful on one account (see ${ }^{19} \mathrm{~F}$ NMR in Figure 2D), but led to insoluble material in other attempts (Scheme 3B).

Three carbonylthio reagents were used, with the aim of enabling the wide range of 'RAFT end group chemistries ${ }^{, 49}, 61$ for polymer side group modification. Potassium thioacetate showed reasonably high reactivity toward pPFBMA, but the expected tetrafluorophenyl thioacetate product was too reactive to be isolated with products containing about $30 \mathrm{~mol}-\%$ of thiols (Scheme 3C). A trithiocarbonate-based nucleophile, Scheme 3D, on the other hand, was less reactive (presumably due to resonance stabilization of the anion) and gave $90 \%$ para-fluoro substitution after heating to $65^{\circ} \mathrm{C}$ for 6 days. At a higher temperature of $80{ }^{\circ} \mathrm{C}$, cleavage of the methacrylic esters was observed and the reaction was deemed impractical for this study. A dithioester-based nucleophile, however, enabled full conversion to the tetrafluorophenyl benzenedithioate derivative within $24 \mathrm{~h}$ at $65^{\circ} \mathrm{C}$, Scheme $3 \mathrm{E}$, based on ${ }^{19} \mathrm{~F}$ NMR spectroscopic analysis (see Table 1). Among several attempts, optimal reaction conditions were an excess of dithioester (1.7 equiv) and of triethylamine (2.8 equiv) in anhydrous DMF. To demonstrate the potential of this benzenedithioate-functionalized species, a sample was aminolysed (releasing thiolate groups) in the presence of butyl acrylate, a thiol-reactive Michael acceptor, giving the ester-functional thiol-ene product in one step, Scheme 3F. ${ }^{1} \mathrm{H}$ NMR spectroscopic analysis confirmed successful modification. SEC analysis, however, revealed a bimodal molar mass distribution, Figure 1F, attributed to a small degree of crosslinking reactions, not uncommon for thiol-functional polymers. ${ }^{62}$ 
It is briefly mentioned that modification attempts of pPFBMA with thiourea, tetrabutylammonium bromide, and tetrabutylammonium iodide (DMF, 2.5 equiv, $80{ }^{\circ} \mathrm{C}, 2$ days) gave no reactions, demonstrating higher selectivity and stability of pPFBMA toward nucleophiles compared to common haloalkane substrates.

\section{Polymer Modification: Amines}

The arguably most important class of nucleophiles for polymer modification comprises amines. Modification of pPFBMA was investigated with a selection of aromatic, primary, and secondary amines. Amines were used in excess (2.5 equiv) and reactions were stirred at 50 or 60 ${ }^{\circ} \mathrm{C}$ in DMF until ${ }^{19} \mathrm{~F}$ NMR spectroscopic analysis of a withdrawn sample indicated complete disappearance of signals associated with the starting material. Products were isolated by precipitation or dialysis and characterized by ${ }^{1} \mathrm{H}$ and ${ }^{19} \mathrm{~F}$ NMR spectroscopy, FT-IR spectroscopy and SEC. Reactions are summarized in Table 4 with structures of amines shown in Scheme 4. 
Table 4. Overview of reaction conditions, molar composition of products and SEC results for postpolymerization modifications of pPFBMA with amines. ${ }^{a}$

\begin{tabular}{|c|c|c|c|c|c|c|c|c|c|}
\hline \multirow[t]{2}{*}{ Entry } & \multirow[t]{2}{*}{ Amine } & \multirow[t]{2}{*}{$\begin{array}{l}T \\
\left({ }^{\circ} \mathbf{C}\right)\end{array}$} & \multirow[t]{2}{*}{$\begin{array}{l}\text { Reaction } \\
\text { time (h) }\end{array}$} & \multirow{2}{*}{$\begin{array}{l}\begin{array}{l}\text { Disubstitution } \\
(\mathrm{Z})^{\mathbf{b}}\end{array} \\
\left(-\mathrm{C}_{6} \mathbf{F}_{4}\right)_{2} \mathrm{NR} \\
(\mathbf{m o l}-\%)\end{array}$} & \multicolumn{2}{|c|}{$\begin{array}{l}\text { Before } \\
\text { Modification }\end{array}$} & \multicolumn{2}{|c|}{$\begin{array}{l}\text { After } \\
\text { Modification }\end{array}$} & \multirow[t]{2}{*}{ Comments } \\
\hline & & & & & $\begin{array}{c}M_{\mathrm{n}}^{\mathrm{SEC}} \\
(\mathrm{kg} / \mathrm{mol})\end{array}$ & $\bar{D}^{\mathrm{SEC}}$ & $\begin{array}{c}M_{\mathrm{n}}^{\mathrm{SEC}} \\
(\mathrm{kg} / \mathrm{mol})\end{array}$ & $\overline{\boldsymbol{D}^{\mathrm{SEC}}}$ & \\
\hline 1 & Aniline & 60 & 10 & & 8.6 & 1.15 & - & - & no reaction \\
\hline 2 & $n$-Butylamine & 50 & 15 & 8 & 8.6 & 1.15 & 10.0 & 1.11 & \\
\hline 3 & $n$-Pentylamine & 60 & 10 & 6 & 8.6 & 1.15 & n.d. & n.d. & \\
\hline 4 & Cyclohexylamine & 60 & 10 & 9 & 8.6 & 1.15 & n.d. & n.d. & \\
\hline 5 & $\begin{array}{l}\text { 3-(Dimethylamino)- } \\
\text { propylamine }\end{array}$ & 60 & 10 & 7 & 8.6 & 1.15 & 49.0 & 1.14 & \\
\hline 6 & $\begin{array}{l}\text { Di(ethylene glycol) } \\
\text { methyl ether amine }\end{array}$ & 50 & 69 & 28 & 16.3 & 1.14 & 19.4 & 1.27 & $\begin{array}{l}\text { water } \\
\text { insoluble }\end{array}$ \\
\hline 7 & $\begin{array}{l}\text { Tri(ethylene glycol) } \\
\text { methyl ether amine }\end{array}$ & 50 & 69 & 28 & 16.3 & 1.14 & 18.1 & 1.21 & $\begin{array}{l}\text { water } \\
\text { insoluble }\end{array}$ \\
\hline 8 & $\begin{array}{l}\mathrm{PEG}_{350} \text { methyl ether } \\
\text { amine }\end{array}$ & 50 & 144 & 26 & 16.3 & 1.14 & 23.7 & 1.25 & $\begin{array}{l}\text { LCST } T_{\mathrm{CP}} \\
40^{\circ} \mathrm{C}^{\mathrm{c}}\end{array}$ \\
\hline 9 & Piperidine & 50 & 15 & 0 & 8.6 & 1.15 & 7.9 & 1.15 & \\
\hline 10 & 4-Benzylpiperidine & 50 & 24 & 0 & 16.3 & 1.14 & n.d. & n.d. & \\
\hline 11 & $\begin{array}{l}\text { 1-(2- } \\
\text { hydroxyethyl)piperazine }\end{array}$ & 50 & 64 & 0 & 16.3 & 1.14 & 25.5 & 1.13 & $\begin{array}{l}\text { pH- } \\
\text { responsive }\end{array}$ \\
\hline
\end{tabular}

${ }^{a}$ In all cases, 2.5 equiv of amine were used in anhydrous $N, N$-dimethylformamide as solvent. With the exception of aniline, complete disappearance of PFBMA repeat units was confirmed by ${ }^{19}$ F NMR spectroscopy. ${ }^{b}$ see Scheme 4A; ${ }^{c}$ LCST-type cloud point (onset of transmittance decrease) of an aqueous solution at a concentration of $5 \mathrm{~g} / \mathrm{L}$. 
Scheme 4. para-Fluoro postpolymerization modification of pPFBMA with amines: Formation of copolymers comprising the expected $N$-functional tetrafluoroaniline side groups (X) as well as $N, N$-bis(tetrafluoroaniline) side groups $(\mathrm{Z})$ for the reaction with primary amines $(\mathbf{A}){ }^{\text {a }}$ proposed mechanism for formation of disubstituted species (B), and modification of pPFBMA with secondary amines in the absence of side reactions $(\mathbf{C})$. 

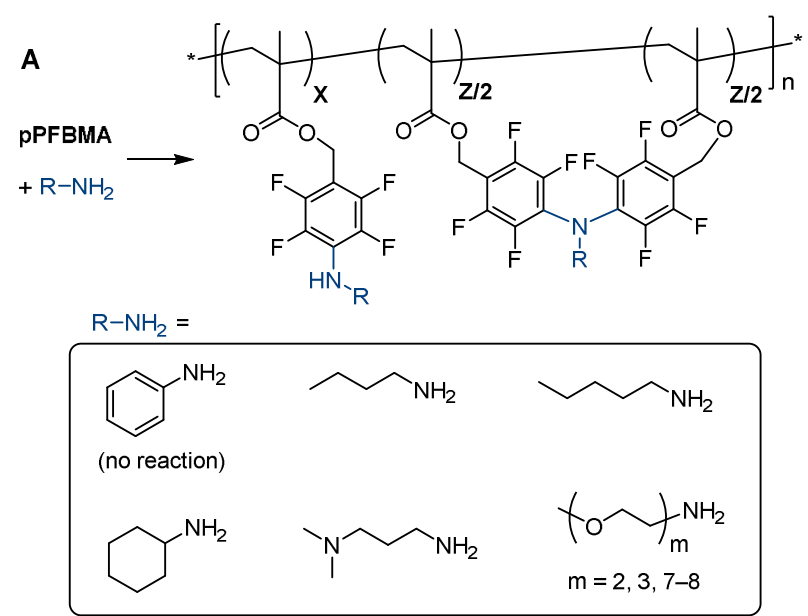

B

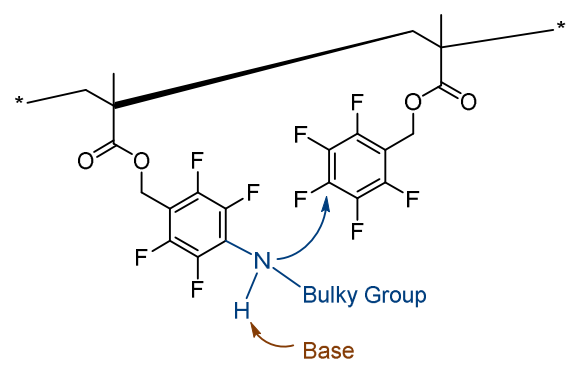

C
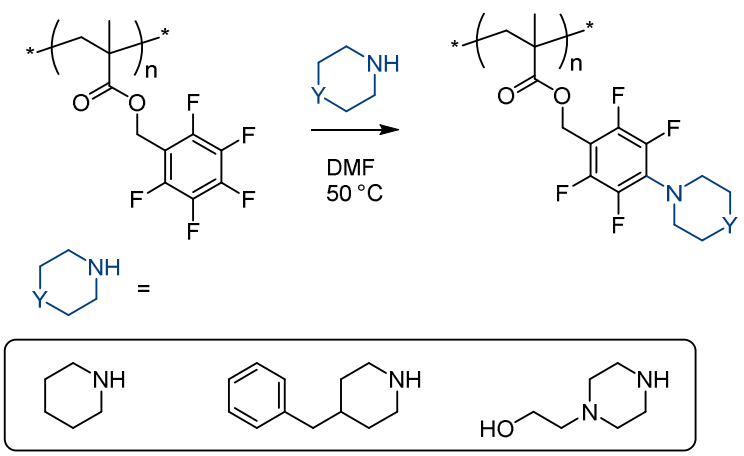

a the molar composition $(\mathrm{X}, \mathrm{Z})$ can be estimated from the number of $\mathrm{R}$ groups per repeat unit $(=\mathrm{X}+\mathrm{Z} / 2)$ obtained from ${ }^{1} \mathrm{H}$ NMR spectroscopy and the percentage of $N, N$-disubstituted tetrafluoroaniline groups $(=\mathrm{Z})$ from ${ }^{19} \mathrm{~F}$ NMR spectroscopy, see Table 4.

For reactions with aniline, Table 4 Entry 1, no para-fluoro substitution occurred and pristine pPFBMA starting material was recovered. Being less nucleophilic than aliphatic amines, aromatic amines typically show lower reactivity in nucleophilic substitution reactions. In case of 
pPFBMA, under the investigated reaction conditions this reactivity difference was sufficiently large to result in selective modification with aliphatic amines only.

For all the employed aliphatic amines, reaction rates were lower than for thiols, with reactions requiring heating to $50-60{ }^{\circ} \mathrm{C}$ overnight for reagents $n$-butylamine, $n$-pentylamine, cyclohexylamine, 3-(dimethylamino)-propylamine, piperidine, and 4-benzyl piperidine, and for 3-6 days for the sterically more demanding oligo(ethylene glycol)-based amines and 1-(2hydroxyethyl)piperazine. As such, pPFPMA appeared to show higher reactivity toward amines at $50{ }^{\circ} \mathrm{C}$ than poly $(2,3,4,5,6$-pentafluorostyrene), which was shown not to react at this temperature $(24 \mathrm{~h}, 50 \text { equiv of amines })^{27}$ and to require microwave-assisted heating to $95^{\circ} \mathrm{C}$ ( $20 \mathrm{~min}, 10$ equiv of amines). ${ }^{29,}{ }^{63}$ Under our reaction conditions, no evidence of acyl substitution or substitution of ortho- or meta- fluorides was observed. SEC analysis of amine-modified products yielded elugrams of similar shape and width as those of the respective pPFBMA starting materials, with the exception of modification with the oligo(ethylene glycol)-based amines, where shoulders toward higher molar masses and slightly increased dispersities were found (Figure 1CDE and Table 4). FT-IR analysis of the oligo(ethylene glycol)methyl ether aminemodified samples confirmed stronger absorbances of $\mathrm{C}-\mathrm{H}$ and $\mathrm{C}-\mathrm{O}$ bonds with an increasing length of the ethylene glycol-based side chains (Figure S12). For all primary amines, ${ }^{19} \mathrm{~F}$ NMR spectroscopy confirmed complete modification through the disappearance of the starting material signals and the appearance of resonances characteristic of $\mathrm{N}$-alkyl tetrafluoroaniline products (Table 1 and Figure 2EF). Surprisingly, however, ${ }^{19} \mathrm{~F}$ NMR spectra also contained signals associated with $N, N$-dialkyl tetrafluoroaniline side groups. The amount of disubstituted aromatic rings ranged from $6-9$ mol- $\%$ for the set of smaller primary amines (Table 4 Entries 2-5, representative ${ }^{19} \mathrm{~F}$ NMR spectrum in Figure $2 \mathrm{E}$ ) to $26-28$ mol- $\%$ found for the oligo(ethylene 
glycol) methyl ether amine-modified samples (Table 4 Entries 6-8, representative ${ }^{19} \mathrm{~F}$ NMR spectrum in Figure 2F). Plausibly, double substitutions occurred, in which $N$-alkyl tetrafluoroaniline side groups (the secondary amines formed through the intended substitution reaction) attacked another PFB group forming $N$-alkyl- $N, N$-bis (tetrafluorophenyl) tertiary amines, see Scheme 4B. With only small (or no) measured increases in dispersity, it is assumed that the majority of such double substitutions occurred intramolecularly, possibly, as shown in Scheme 4B, with the neighboring group. Double substitutions have previously been described for reactions of low molar mass PFB derivatives with amines. ${ }^{64-67}$ In fact, Costa et al. ${ }^{64}$ recently described the reaction of a primary amine with hexafluorobenzene, which produced only the doubly substituted tertiary amine derivate and recovered unreacted primary amine. The higher reactivity of the secondary amine intermediate was attributed to a higher $\mathrm{N}-\mathrm{H}$ acidity caused by the fluorinated substituent. The proposed double substitution on the polymeric substrate was in agreement with ${ }^{1} \mathrm{H}$ NMR results, Figure S13. For example, for the modification of pPFBMA with di(ethylene glycol) methyl ether amine (DEG) (Table 4, entry 6), ${ }^{1} \mathrm{H}$ NMR analysis indicated an average presence of 0.86 DEG side chains per repeat unit (Figure S13B). To reiterate, ${ }^{19} \mathrm{~F}$ NMR spectroscopic analysis of this sample indicated that $28 \%$ of aryl side groups formally contributed half a functional group, equivalent to a substitution efficiency of 0.86 (= $100 \%-1 / 2 \times 28 \%$ ) DEG side chains per repeat unit, in excellent agreement with the ${ }^{1} \mathrm{H}$ NMR interpretation.

Despite the unexpected side reactions the modification of pPFBMA with amines has potential in producing 'smart' polymers. The modification of pPFBMA with di- and tri(ethylene glycol) methyl ether amine (Table 4 Entries 6, 7) resulted in water insoluble products. Addition of acid (until $\mathrm{pH} \sim 3$ ) did not improve solubility, suggesting no significant amount of protonation of the 
tetrafluoroaniline nitrogen atoms and confirming their low basicity (the conjugate acid of the comparable small molecule pentafluoroaniline (i.e., $\mathrm{F}_{5} \mathrm{C}_{6} \mathrm{NH}_{3}{ }^{+}$) has a reported $\left.\mathrm{p} K_{\mathrm{a}}=-0.3\right){ }^{68}$ The modification of pPFBMA with PEG $_{350}$ methyl ether amine, however, yielded a product with temperature-dependent aqueous solubility (below a critical temperature) and measured LCSTtype cloud points around body temperature (Figure S14-S15). As such, this pPFBMA-derived species represents a new addition to the PEG-based family of materials with similar stimulusresponsive solution behavior. ${ }^{69,70}$

Yet, copolymer formation and lack of compositional control make the modification of pPFBMA with primary amines unideal for the preparation of well-defined polymers. Gratifyingly, the modification of pPFBMA with the secondary amine piperidine (Table 4 Entry 9) was found to proceed without side reactions with ${ }^{19} \mathrm{~F}$ NMR analysis showing only the expected tertiary amine functionality (Figure $2 \mathrm{G}$ ) and ${ }^{1} \mathrm{H}$ NMR measurements indicating the quantitative presence of the expected cyclic substituent (Figure 3D). FT-IR analysis showed the absence of $\mathrm{N}-\mathrm{H}$ stretching (around $v=3500-3300 \mathrm{~cm}^{-1}$ ) and $\mathrm{N}-\mathrm{H}$ bending (around $v=1640-$ $1550 \mathrm{~cm}^{-1}$, Figure 4) vibrations and a red-shift of the $\mathrm{C}=\mathrm{C}$ aromatic vibrations from $v\left(\mathrm{C}_{6} \mathrm{~F}_{5}\right)=$ $1504 \mathrm{~cm}^{-1}$ to $v\left(\mathrm{C}_{6} \mathrm{~F}_{4} \mathrm{NR}_{2}\right)=1484 \mathrm{~cm}^{-1}$ (Figure 4 , inset), confirming aromatic substitution. Based on these results, two further secondary amines, including an $N$-functional piperazine, (Table 4 , Entries 10-11; Scheme 4C) were tested and found to react quantitatively in 24-64 h without observed side reactions (see ${ }^{1} \mathrm{H}$ NMR data in Figure 3E). By virtue of its tertiary amine functionality, the 1-(2-hydroxyethyl)piperazine-functional polymer was soluble in dilute aq. $\mathrm{HCl}$ ( $\mathrm{pH}$ 5-6) but precipitated above $\mathrm{pH} 7$ when aq. $\mathrm{NaHCO}_{3}$ was added, demonstrating the preparation of a $\mathrm{pH}-$-responsive polymer from the pPFPMA platform (Figure S16-17) . 


\section{Zwitterionic Temperature-responsive Polymers}

Finally, having shown selective quantitative postpolymerization modification reactions of pPFBMA with sulfur- and nitrogen based nucleophiles, their potential in the development of novel zwitterionic polymers with upper critical solution temperature (UCST) behavior in water is presented as a proof-of-concept. This 'smart' behavior involving solubility above a critical temperature is known only for very few types of polymers, ${ }^{71}$ including some zwitterionic sulfobetaines. $^{72,73}$ Our group recently established that introduction of aromatic functionality into sulfobetaine co- and terpolymers can be beneficial in increasing UCST transition temperatures, realizing UCST transitions at physiologically relevant $\mathrm{NaCl}$ concentration, ${ }^{74,75}$ and in designing terpolymers with an LCST and UCST (miscipility gap) ${ }^{76}$ Exploiting the postpolymerization of pPFBMA, zwitterionic and aromatic functionality could easily be included into the same repeat unit.

Samples of 2-(dimethylamino)ethanethiol-modified pPFBMA 70 (Table 3 Entry 5) were quaternized with 1,3-propane sultone $\left(5\right.$ days, $\left.40^{\circ} \mathrm{C}\right)$ and with 1,4-butane sultone $\left(15 \mathrm{~h}, 120^{\circ} \mathrm{C}\right.$, microwave heating), followed by dialysis against water, Scheme 5. Microwave heating was necessary to push the reaction with the commonly sluggish ${ }^{75}$ 1,4-butanesultone to completion (Figure S18). 
Scheme 5. Successive postpolymerization modification of tertiary-amine functional pPFBMA $_{70}$ derivative with 1,3 propanesultone (A) and 1,4 butanesultone (B) giving the

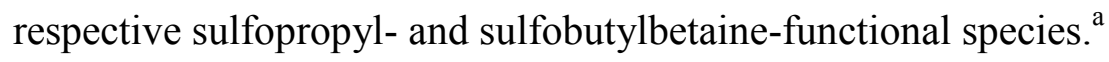

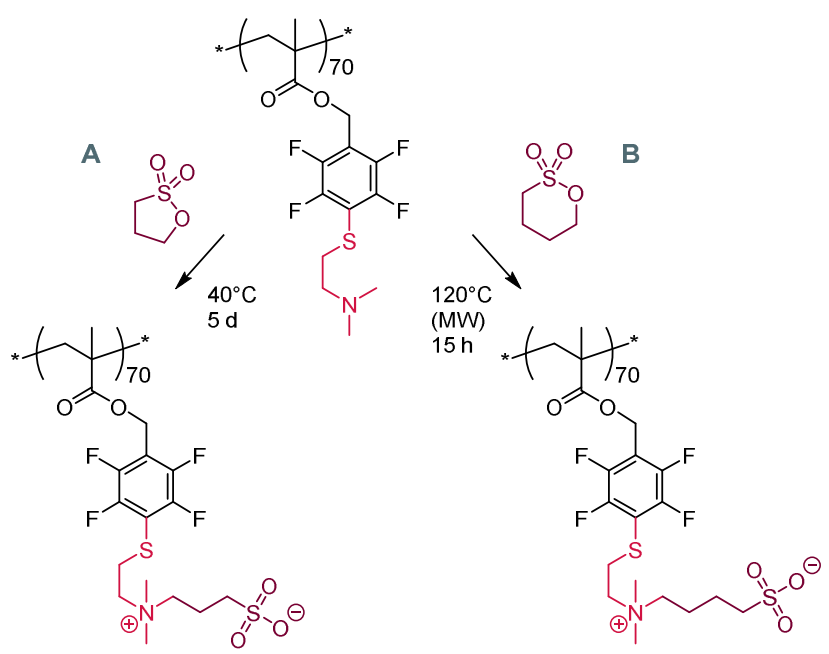

a reactions were performed in 2,2,2-trifluoroethanol in which reagents and products were soluble.

\footnotetext{
${ }^{19} \mathrm{~F}$ NMR spectroscopic analysis of the zwitterionic homopolymers in $\mathrm{D}_{2} \mathrm{O} / \mathrm{NaBr}$ revealed essentially no change of ${ }^{19} \mathrm{~F}$ chemical shifts compared to the tertiary amine precursor, but peaks were broadened drastically which suggested poor hydration of the hydrophobic fluorinated aromatic in the aqueous solvent (Figure 5).
} 


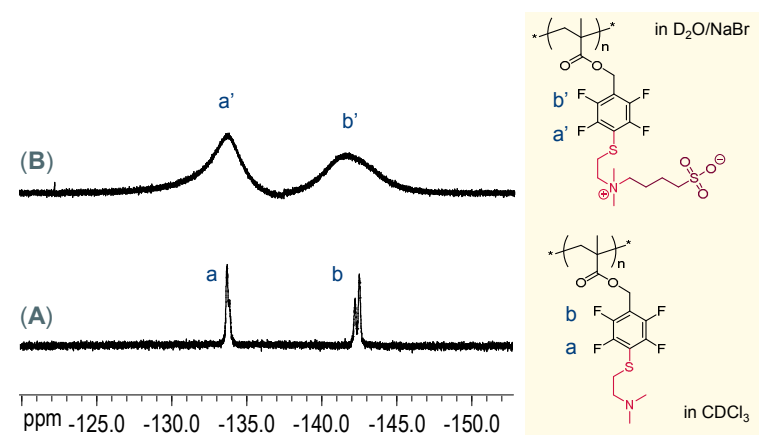

Figure 5. ${ }^{19} \mathrm{~F}$ NMR spectra of the tertiary amine-functional precursor (A) and after quaternization with 1,4-butanesultone showing peak broadening (B) with solvents and peak assignments indicated.

The two novel zwitterionic homopolymers showed the desired UCST behavior in water with measured UCSTs of $56^{\circ} \mathrm{C}$ (sulfopropylbetaine species) and $70{ }^{\circ} \mathrm{C}$ (sulfobutylbetaine species), see Figure 6A for temperature-concentration phase diagram and Figure S19-S21 for transmittance curves. Analogous methacrylic sulfobetaines of a similar degree of polymerization but lacking the aromatic ring can be expected to have much lower transition temperatures or to be fully soluble in water within the observable temperature range of $0-100{ }^{\circ} \mathrm{C},{ }^{75}$ demonstrating the effect of the aromatic group on decreasing solubility. The UCST transition temperature was found, expectedly, to decrease with an increasing concentration of added $\mathrm{NaCl}$, Figure $6 \mathrm{~B}$, with approximately linear decreases found for both species, though, surprisingly, with a larger slope for the sulfobutylbetaine homopolymer. Fortuitously, the sulfopropylbetaine derivative showed measurable cloud points up to $\mathrm{NaCl}$ concentrations of $178 \mathrm{mM}$, above the physiological 
concentration of approx. $154 \mathrm{mM}$. This data demonstrates the potential in developing novel smart homopolymers without the need for tuning through copolymerization as was previously done to achieve UCST transitions at such high salt concentrations.
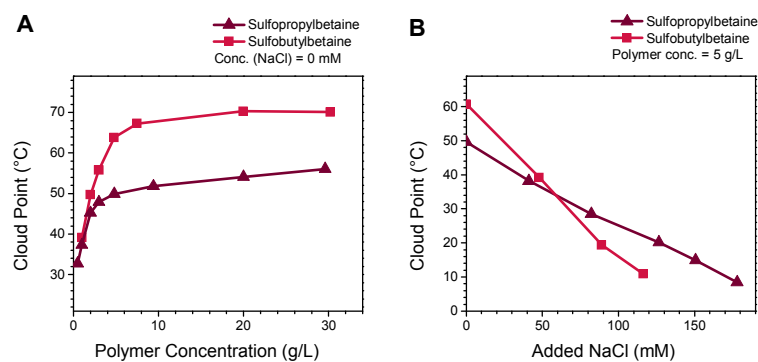

Figure 6. Temperature-concentration phase diagram indicating the temperatures above which the sulfopropylbetaine homopolymer (triangles) and the sulfobutylbetaine homopolymer (squares) were found to be soluble in pure water (A) and transition temperatures of both species in dependence of added $\mathrm{NaCl}(\mathbf{B})$

\section{Conclusion}

A novel reactive polymer scaffold was introduced that benefits from high-yielding, one-step monomer synthesis, well-controlled methacrylate RAFT polymerization, polymer solubility in a wide range of organic solvents, and efficient and selective postpolymerizaton modification options. Poly(2,3,4,5,6-pentafluorobenzyl methacrylate) (pPFBMA) showed high reactivity toward thiols, comparable to that of $\operatorname{poly}(2,3,4,5,6$-pentafluorostyrene), reacting to completion within an hour at room temperature. The resulting para-substituted aromatic structure was exploited herein for the preparation of novel zwitterionic homopolymers that showed aqueous 
UCST transition temperatures within a wide temperature and $\mathrm{NaCl}$ concentration range. Reactions of pPFBMA with various amines did not result in ester cleavage reactions common of the activated ester pentafluorophenyl methacrylate analogues but proceeded with selective and quantitative substitution of the para-fluorides. For the use of primary amines, especially for sterically demanding reagents, a disubstitution side reaction was observed which resulted in a lower-than-expected presence of functional groups (minimum observed degree of functionalization 86\%) and slightly increased molar mass dispersities (largest observed increase $Ð=1.14$ to $Ð=1.27)$. Nonetheless, modification of pPFBMA with a PEG-based amine produced a novel species with an aqueous LCST transition. Side reactions were not observed for the reaction of pPFBMA with piperidine and piperazine derivatives for which quantitative and selective side group modification was found. For the first time, the performance of other nucleophiles in para-fluoro postpolymerization substitution was investigated, with pPFBMA proving to be stable toward halides, thiosulfonate, and thiourea. Modification with carbonylthio compounds, however, was successful and allowed for subsequent one-pot aminolysis, in situ release of tetrafluorophenylthiols, and their capture through thia-Michael 'click' modification, albeit accompanied by a broadening of the molar mass distribution. ${ }^{19} \mathrm{~F}$ NMR spectroscopy served as an expedient tool throughout the study, proving effective to determine tacticity and follow modification reactions. A reference list of ${ }^{19} \mathrm{~F}$ NMR chemical shifts was compiled. Given the synthetic importance of postpolymerization modification, it is believed that this selectively reactive methacrylic system will find wide-spread applications in synthetic polymer science. 
Supporting Information. Synthesis of 2,3,4,5,6-pentafluorobenzyl acrylate, ${ }^{1} \mathrm{H},{ }^{13} \mathrm{C},{ }^{19} \mathrm{~F}$ NMR and FT-IR spectra of monomers, ${ }^{1} \mathrm{H}$-coupled and ${ }^{1} \mathrm{H}$-decoupled spectra of 2,3,4,5,6pentafluorotoluene and after modification with thiophenol, ${ }^{1} \mathrm{H}-{ }^{13} \mathrm{C} \mathrm{HSQC}$ and ${ }^{19} \mathrm{~F}-{ }^{19} \mathrm{~F} \mathrm{COSY}$ NMR spectra of pPFBMA, FT-IR spectra of oligo(ethylene glycol) methyl ether amine-modified polymers, additional ${ }^{1} \mathrm{H}$ NMR spectra of amine-modified polymers, photographs of $\mathrm{pH}$ responsive polymer, ${ }^{1} \mathrm{H}$ NMR spectra of zwitterionic polymer and its precursor, and turbidity curves and phase diagrams of thermoresponsive polymers.

Acknowledgement. Funding for J.-M. N. from the Faculty of Engineering at the University of New South Wales is acknowledged. P.J.R. acknowledges Ms. Georgia Khinsoe (All Saints' College, Perth) for performing turbidity measurements, Mr. Elden Garrett (Curtin University) for assistance with microwave heating experiments, Mrs. Violeta Doukova (University of Surrey) for DSC measurements, and Prof. Andrew B. Lowe, Prof. Mark Buntine, the Nanochemistry Research Institute (NRI), and the Department of Chemistry at Curtin University for support. 
For Table of Contents Use Only

Para-Fluoro Postpolymerization Chemistry of Poly(pentafluorobenzyl methacrylate): Modification with Amines, Thiols, and Carbonylthiolates

Janina-Miriam Noy, Ann-Katrin Friedrich, Kyle Batten, Mathamsanqa N. Bhebhe, Nicolas Busatto, Rhiannon R. Batchelor, Ariella Kristanti, Yiwen Pei, Peter J. Roth*

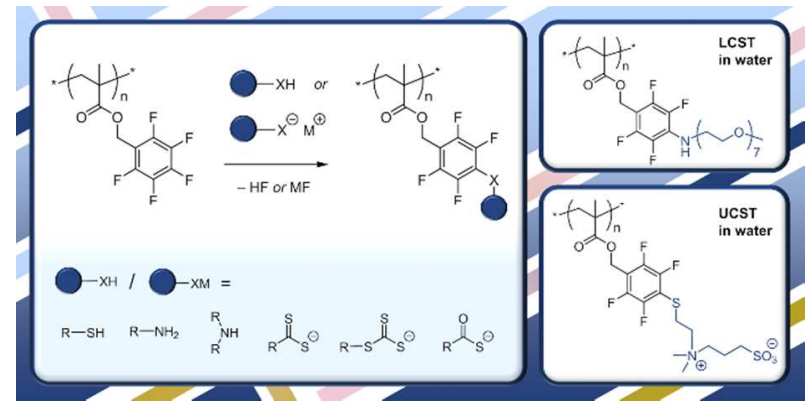




\section{References}

1. Günay, K. A.; Theato, P.; Klok, H.-A. Standing on the shoulders of Hermann Staudinger: Post-polymerization modification from past to present. Journal of Polymer Science Part A: Polymer Chemistry 2013, 51 (1), 1-28 DOI: 10.1002/pola.26333.

2. Gauthier, M. A.; Gibson, M. I.; Klok, H.-A. Synthesis of Functional Polymers by PostPolymerization Modification. Angewandte Chemie International Edition 2009, 48 (1), 4858 DOI: 10.1002/anie.200801951.

3. Jo, H.; Theato, P., Post-polymerization Modification of Surface-Bound Polymers. In Controlled Radical Polymerization at and from Solid Surfaces, Vana, P., Ed. Springer International Publishing: Cham, 2016; pp 163-192.

4. Romulus, J.; Henssler, J. T.; Weck, M. Postpolymerization Modification of Block Copolymers. Macromolecules 2014, 47 (16), 5437-5449 DOI: 10.1021/ma5009918.

5. Roth, P. J. Composing Well-Defined Stimulus-Responsive Materials Through Postpolymerization Modification Reactions. Macromolecular Chemistry and Physics 2014, 215 (9), 825-838 DOI: 10.1002/macp.201400073.

6. Edmondson, S.; Huck, W. T. S. Controlled growth and subsequent chemical modification of poly(glycidyl methacrylate) brushes on silicon wafers. Journal of Materials Chemistry 2004, 14 (4), 730-734 DOI: 10.1039/B312513K.

7. Zhang, Q.; Anastasaki, A.; Li, G.-Z.; Haddleton, A. J.; Wilson, P.; Haddleton, D. M. Multiblock sequence-controlled glycopolymers via $\mathrm{Cu}(0)$-LRP following efficient thiolhalogen, thiol-epoxy and CuAAC reactions. Polymer Chemistry 2014, 5 (12), 3876-3883 DOI: 10.1039/C4PY00320A.

8. Buck, M. E.; Lynn, D. M. Azlactone-functionalized polymers as reactive platforms for the design of advanced materials: Progress in the last ten years. Polymer Chemistry 2012, 3 (1), 66-80 DOI: 10.1039/C1PY00314C.

9. Carter, M. C. D.; Lynn, D. M. Covalently Crosslinked and Physically Stable Polymer Coatings with Chemically Labile and Dynamic Surface Features Fabricated by Treatment of Azlactone-Containing Multilayers with Alcohol-, Thiol-, and Hydrazine-Based Nucleophiles. Chemistry of Materials 2016, 28 (14), 5063-5072 DOI: 10.1021/acs.chemmater.6b01897. 
10. Ho, H. T.; Levere, M. E.; Fournier, D.; Montembault, V.; Pascual, S.; Fontaine, L. Introducing the Azlactone Functionality into Polymers through Controlled Radical Polymerization: Strategies and Recent Developments. Australian Journal of Chemistry 2012, 65 (8), 970-977 DOI: http://dx.doi.org/10.1071/CH12192.

11. Zhu, Y.; Quek, J. Y.; Lowe, A. B.; Roth, P. J. Thermoresponsive (Co)polymers through Postpolymerization Modification of Poly(2-vinyl-4,4-dimethylazlactone). Macromolecules 2013, 46 (16), 6475-6484 DOI: 10.1021/ma401096r.

12. Das, A.; Theato, P. Activated Ester Containing Polymers: Opportunities and Challenges for the Design of Functional Macromolecules. Chemical Reviews 2016, 116 (3), 1434-1495 DOI: 10.1021/acs.chemrev.5b00291.

13. Roth, P. J.; Theato, P., Polymer Analogous Reactions. In Reference Module in Materials Science and Materials Engineering, Elsevier: 2016.

14. Durmaz, H.; Sanyal, A.; Hizal, G.; Tunca, U. Double click reaction strategies for polymer conjugation and post-functionalization of polymers. Polymer Chemistry 2012, 3 (4), 825 835 DOI: 10.1039/C1PY00471A.

15. Battioni, P.; Brigaud, O.; Desvaux, H.; Mansuy, D.; Traylor, T. G. Preparation of functionalized polyhalogenated tetraaryl-porphyrins by selective substitution of the pFluorines of meso-tetra-(pentafluorophenyl)porphyrins. Tetrahedron Letters 1991, 32 (25), 2893-2896 DOI: http://dx.doi.org/10.1016/0040-4039(91)80641-I.

16. Chambers, R. D.; Close, D.; Williams, D. L. H. Mechanisms for reactions of halogenated compounds. Part 3. Variation in activating influence of halogen substituents in nucleophilic aromatic substitution. Journal of the Chemical Society, Perkin Transactions 2 1980, (5), 778-780 DOI: 10.1039/p29800000778.

17. Kvíčala, J.; Beneš, M.; Paleta, O.; Král, V. Regiospecific nucleophilic substitution in 2,3,4,5,6-pentafluorobiphenyl as model compound for supramolecular systems. Theoretical study of transition states and energy profiles, evidence for tetrahedral SN2 mechanism. Journal of Fluorine Chemistry 2010, 131 (12), 1327-1337 DOI: http://dx.doi.org/10.1016/j.jfluchem.2010.09.003.

18. Ma, J.; Cheng, C.; Sun, G.; Wooley, K. L. Well-Defined Polymers Bearing Pendent Alkene Functionalities via Selective RAFT Polymerization. Macromolecules 2008, 41 (23), 9080-9089 DOI: 10.1021/ma802057u. 
19. Lu, W.; An, X.; Gao, F.; Zhu, J.; Zhou, N.; Zhang, Z.; Pan, X.; Zhu, X. Highly Efficient Chain End Derivatization of Selenol-Ended Polystyrenes by Nucleophilic Substitution Reactions. Macromolecular Chemistry and Physics 2017, 218 (4), 1600485-n/a DOI: 10.1002/macp.201600485.

20. Wild, A.; Winter, A.; Hager, M. D.; Görls, H.; Schubert, U. S. PerfluorophenylTerpyridine Ruthenium Complex as Monomer for Fast, Efficient, and Mild Metallopolymerizations. Macromolecular Rapid Communications 2012, 33 (6-7), 517-521 DOI: $10.1002 /$ marc.201100711.

21. Gan, D.; Mueller, A.; Wooley, K. L. Amphiphilic and hydrophobic surface patterns generated from hyperbranched fluoropolymer/linear polymer networks: Minimally adhesive coatings via the crosslinking of hyperbranched fluoropolymers. Journal of Polymer Science Part A: Polymer Chemistry 2003, 41 (22), 3531-3540 DOI: 10.1002/pola.10968.

22. Cavalli, F.; Mutlu, H.; Steinmueller, S. O.; Barner, L. The para-fluoro-thiol reaction as a powerful tool for precision network synthesis. Polymer Chemistry 2017, 8 (25), 3778-3782 DOI: 10.1039/C7PY00812K.

23. Boufflet, P.; Casey, A.; Xia, Y.; Stavrinou, P. N.; Heeney, M. Pentafluorobenzene endgroup as a versatile handle for para fluoro "click" functionalization of polythiophenes. Chemical Science 2017, 8 (3), 2215-2225 DOI: 10.1039/C6SC04427A.

24. Cakir, N.; Tunca, U.; Hizal, G.; Durmaz, H. Heterofunctionalized Multiarm Star Polymers via Sequential Thiol-para-Fluoro and Thiol-Ene Double "Click” Reactions.

Macromolecular Chemistry and Physics 2016, 217 (5), 636-645 DOI: 10.1002/macp.201500300.

25. Noy, J.-M.; Koldevitz, M.; Roth, P. J. Thiol-reactive functional poly(meth)acrylates: multicomponent monomer synthesis, RAFT (co)polymerization and highly efficient thiolpara-fluoro postpolymerization modification. Polym. Chem. 2015, 6 (3), 436-447 DOI: 10.1039/c4py01238k.

26. Pei, Y.; Noy, J.-M.; Roth, P. J.; Lowe, A. B. Thiol-reactive Passerini-methacrylates and polymorphic surface functional soft matter nanoparticles via ethanolic RAFT dispersion polymerization and post-synthesis modification. Polymer Chemistry 2015, 6 (11), 19281931 DOI: 10.1039/C4PY01558D. 
27. Varadharajan, D.; Delaittre, G. Accessing libraries of bifunctional block copolymers using two distinct pentafluorophenyl moieties. Polymer Chemistry 2016, 7 (48), 7488-7499 DOI: 10.1039/C6PY01711H.

28. Bhebhe, M. N.; De Eulate, E. A.; Pei, Y.; Arrigan, D. W. M.; Roth, P. J.; Lowe, A. B. Reactive Conjugated Polymers: Synthesis, Modification, and Electrochemical Properties of Polypentafluorophenylacetylene (Co)Polymers. Macromolecular Rapid Communications 2017, 38 (2), 1600450-n/a DOI: 10.1002/marc.201600450.

29. Ott, C.; Hoogenboom, R.; Schubert, U. S. Post-modification of poly(pentafluorostyrene): a versatile "click" method to create well-defined multifunctional graft copolymers. Chemical Communications 2008, (30), 3516-3518 DOI: 10.1039/b807152g.

30. Atanasov, V.; Kerres, J. Highly Phosphonated Polypentafluorostyrene. Macromolecules 2011, 44 (16), 6416-6423 DOI: 10.1021/ma2011574.

31. Atanasov, V.; Bürger, M.; Lyonnard, S.; Porcar, L.; Kerres, J. Sulfonated poly(pentafluorostyrene): Synthesis \&amp; characterization. Solid State Ionics 2013, 252 (0), 75-83 DOI: http://dx.doi.org/10.1016/j.ssi.2013.06.010.

32. Becer, C. R.; Babiuch, K.; Pilz, D.; Hornig, S.; Heinze, T.; Gottschaldt, M.; Schubert, U. S. Clicking Pentafluorostyrene Copolymers: Synthesis, Nanoprecipitation, and Glycosylation. Macromolecules 2009, 42 (7), 2387-2394 DOI: 10.1021/ma9000176.

33. Riedel, M.; Stadermann, J.; Komber, H.; Simon, F.; Voit, B. Synthesis, post-modification and self-assembled thin films of pentafluorostyrene containing block copolymers.

European Polymer Journal 2011, 47 (4), 675-684 DOI: http://dx.doi.org/10.1016/j.eurpolymj.2010.10.010.

34. Turgut, H.; Schmidt, A. C.; Wadhwani, P.; Welle, A.; Muller, R.; Delaittre, G. The parafluoro-thiol ligation in water. Polymer Chemistry 2017, 8 (8), 1288-1293 DOI: 10.1039/c6py02108e.

35. Chen, J.; Dumas, L.; Duchet-Rumeau, J.; Fleury, E.; Charlot, A.; Portinha, D. Tuning hbond capability of hydroxylated-poly(2,3,4,5,6-pentafluorostyrene) grafted copolymers prepared by chemoselective and versatile thiol-para-fluoro "click-type" coupling with mercaptoalcohols. Journal of Polymer Science Part A: Polymer Chemistry 2012, 50 (16), 3452-3460 DOI: 10.1002/pola.26136. 
36. Dumas, L.; Fleury, E.; Portinha, D. Wettability adjustment of PVDF surfaces by combining radiation-induced grafting of $(2,3,4,5,6)$-pentafluorostyrene and subsequent chemoselective “click-type" reaction. Polymer 2014, 55 (11), 2628-2634 DOI: http://dx.doi.org/10.1016/j.polymer.2014.04.002.

37. Yin, Q.; Charlot, A.; Portinha, D.; Beyou, E. Nitroxide-mediated polymerization of pentafluorostyrene initiated by PS-DEPN through the surface of APTMS modified fumed silica: towards functional nanohybrids. RSC Advances 2016, 6 (63), 58260-58267 DOI: 10.1039/C6RA08973A.

38. Turgut, H.; Delaittre, G. On the Orthogonality of Two Thiol-Based Modular Ligations. Chemistry - A European Journal 2016, 22 (4), 1511-1521 DOI: 10.1002/chem.201503844.

39. ten Brummelhuis, N.; Weck, M. Orthogonal Multifunctionalization of Random and Alternating Copolymers. ACS Macro Letters 2012, 1 (10), 1216-1218 DOI: $10.1021 / \mathrm{mz} 300428 \mathrm{n}$.

40. Moad, G.; Rizzardo, E.; Thang, S. H. Living Radical Polymerization by the RAFT Process - A Third Update. Australian Journal of Chemistry 2012, 65 (8), 985-1076 DOI: https://doi.org/10.1071/CH12295.

41. Marita, T.; Hagłwara, T.; Hamana, H.; Shoji, Y. Anionic polymerization of fluorinecontaining vinyl monomers. Polymer Bulletin 1989, 21 (2), 119-124 DOI: 10.1007/bf00266161.

42. Jones, R. G.; Davies, R. D. P.; Brambley, D. R. Comparative evaluation of poly(pentafluoroaryl methacrylate)s and their non-fluorinated analogues as positiveworking electron-beam resists. Journal of Materials Chemistry 1993, 3 (1), 15-18 DOI: 10.1039/JM9930300015.

43. Narita, T.; Hagiwara, T.; Hamana, H.; Dei, K.; Shoji, Y. Synthesis and Q,e Values of New Fluorine-Containing Monomer: Pentafluorophenylmethyl Methacrylate. Polym J 1989, 21 (11), 925-928 DOI: 10.1295/polymj.21.925.

44. Daikos, O.; Naumov, S.; Knolle, W.; Heymann, K.; Scherzer, T. Peculiarities of the photoinitiator-free photopolymerization of pentabrominated and pentafluorinated aromatic acrylates and methacrylates. Physical Chemistry Chemical Physics 2016, 18 (47), 3236932377 DOI: 10.1039/C6CP06549J. 
45. Eberhardt, M.; Mruk, R.; Zentel, R.; Théato, P. Synthesis of pentafluorophenyl(meth)acrylate polymers: New precursor polymers for the synthesis of multifunctional materials. European Polymer Journal 2005, 41 (7), 1569-1575 DOI: http://dx.doi.org/10.1016/j.eurpolymj.2005.01.025.

46. Mazurin, O. V. Problems of compatibility of the values of glass transition temperatures published in the world literature. Glass Physics and Chemistry 2007, 33 (1), 22-36 DOI: 10.1134/s108765960701004x.

47. Boyer, C.; Liu, J.; Wong, L.; Tippett, M.; Bulmus, V.; Davis, T. P. Stability and utility of pyridyl disulfide functionality in RAFT and conventional radical polymerizations. Journal of Polymer Science Part A: Polymer Chemistry 2008, 46 (21), 7207-7224 DOI: 10.1002/pola.23028.

48. Roth, P. J.; Wiss, K. T.; Zentel, R.; Theato, P. Synthesis of Reactive Telechelic Polymers Based on Pentafluorophenyl Esters. Macromolecules 2008, 41 (22), 8513-8519 DOI: 10.1021/ma801681b.

49. Harvison, M. A.; Roth, P. J.; Davis, T. P.; Lowe, A. B. End Group Reactions of RAFTPrepared (Co)Polymers. Australian Journal of Chemistry 2011, 64 (8), 992-1006 DOI: $10.1071 / \operatorname{ch} 11152$.

50. Mandal, T. K.; Woo, E. M. Marginal miscibility and solvent-dependent phase behavior in solution-blended poly(vinyl methyl ether)/poly(benzyl methacrylate). Macromolecular Chemistry and Physics 1999, 200 (5), 1143-1149 DOI: 10.1002/(SICI)15213935(19990501)200:5<1143::AID-MACP1143>3.0.CO;2-S.

51. Jankova, K.; Hvilsted, S. Preparation of Poly(2,3,4,5,6-pentafluorostyrene) and Block Copolymers with Styrene by ATRP. Macromolecules 2003, 36 (5), 1753-1758 DOI: $10.1021 / \mathrm{ma} 021039 \mathrm{~m}$.

52. Fujii, K.; Brownstein, S.; Eastham, A. M. Fluorine magnetic resonance spectra and tacticities of poly(vinyl trifluoroacetate). Journal of Polymer Science Part A-1: Polymer Chemistry 1968, 6 (8), 2387-2396 DOI: 10.1002/pol.1968.150060830.

53. Lenz, R. W.; Regel, W.; Westfelt, L. Cationic polymerization of p-substituted $\alpha$ methylstyrenes, 1 . Tacticity by $1 \mathrm{H}-$ and 19F-NMR spectroscopy. Die Makromolekulare Chemie 1975, 176 (3), 781-787 DOI: 10.1002/macp.1975.021760320. 
54. Li, B.; Zhou, P.; Chen, Y.; Jiang, B.; Zhu, H. Anionic polymerization of fluorinesubstituted phenyl methacrylates. Science China Chemistry 2015, 58 (1), 107-113 DOI: 10.1007/s11426-014-5247-z.

55. Koizumi, S.; Ohmori, A.; Shimizu, T.; Iwami, M. Structual Studies of Poly(Fluoroalkyl Methacrylate)s and Poly(Fluoroalkyl $\alpha$-Fluoroacrylate)s. Japanese Journal of Applied Physics 1992, 31 (10R), 3408.

56. Li, L.; Rinaldi, P. L. Tacticity of Poly(1-chloro-1-fluoroethylene) Fluoropolymer Determined Using 1H/13C/19F Triple-Resonance 3D-NMR. Macromolecules 1996, 29 (13), 4808-4810 DOI: 10.1021/ma9601023.

57. Victor, M. W.; Saffariannour, M.; Reynolds, J. R. Structural Characterization of Poly $(\alpha-$ Fluoroacrylonitrile) and Poly(Ethyl $\alpha$-Fluoroacrylate). Journal of Macromolecular Science, Part A 1994, 31 (6), 721-736 DOI: 10.1080/10601329409349751.

58. Lowe, A. B.; Bowman, C. e., Thiol-X Chemistries in Polymer and Materials Science. Royal Society of Chemistry: 2013.

59. Roth, P. J.; Kessler, D.; Zentel, R.; Theato, P. Versatile $\omega$-end group functionalization of RAFT polymers using functional methane thiosulfonates. Journal of Polymer Science Part A: Polymer Chemistry 2009, 47 (12), 3118-3130 DOI: 10.1002/pola.23392.

60. Quinn, J. F.; Whittaker, M. R.; Davis, T. P. Glutathione responsive polymers and their application in drug delivery systems. Polymer Chemistry 2017, 8 (1), 97-126 DOI: 10.1039/C6PY01365A.

61. Lowe, A. B., CHAPTER 2 End-group Functionalization of RAFT-prepared Polymers Using Thiol-X Chemistries. In Thiol-X Chemistries in Polymer and Materials Science, The Royal Society of Chemistry: 2013; pp 28-58.

62. Zorn, M.; Bae, W. K.; Kwak, J.; Lee, H.; Lee, C.; Zentel, R.; Char, K. Quantum Dot-Block Copolymer Hybrids with Improved Properties and Their Application to Quantum Dot Light-Emitting Devices. ACS Nano 2009, 3 (5), 1063-1068 DOI: 10.1021/nn800790s.

63. Samaroo, D.; Soll, C. E.; Todaro, L. J.; Drain, C. M. Efficient Microwave-Assisted Synthesis of Amine-Substituted Tetrakis(pentafluorophenyl)porphyrin. Organic Letters 2006, 8 (22), 4985-4988 DOI: 10.1021/o1060946z. 
64. Costa, J. I. T.; Farinha, A. S. F.; Neves, M. G. P. M. S.; Tomé, A. C. An easy access to porphyrin triads and their supramolecular interaction with a pyridyl [60]fulleropyrrolidine. Dyes and Pigments 2016, 135, 163-168 DOI:

http://dx.doi.org/10.1016/j.dyepig.2016.02.035.

65. Guardigli, C.; liantonio, R.; lorenza mele, M.; metrangolo, P.; resnati, G.; pilati, T. Design and Synthesis of New Tectons for Halogen Bonding-driven Crystal Engineering. Supramolecular Chemistry 2003, 15 (3), 177-188 DOI: 10.1080/1061027031000078248.

66. Huber, B.; Linder, T.; Hormann, K.; Frömling, T.; Sundermeyer, J.; Roling, B., Synthesis of Novel Lithium Salts containing Pentafluorophenylamido-based Anions and Investigation of their Thermal and Electrochemical Properties. In Zeitschrift für Physikalische Chemie, 2012; Vol. 226, p 377.

67. Kögel, J. F.; Linder, T.; Schröder, F. G.; Sundermeyer, J.; Goll, S. K.; Himmel, D.; Krossing, I.; Kütt, K.; Saame, J.; Leito, I. Fluoro- and Perfluoralkylsulfonylpentafluoroanilides: Synthesis and Characterization of NH Acids for Weakly Coordinating Anions and Their Gas-Phase and Solution Acidities. Chemistry - A European Journal 2015, 21 (15), 5769-5782 DOI: 10.1002/chem.201405391.

68. Shoute, L. C. T.; Mittal, J. P.; Neta, P. Fluoride Elimination upon Reaction of Pentafluoroaniline with $\mathrm{H}$, and $\mathrm{OH}$ Radicals in Aqueous Solution. The Journal of Physical Chemistry 1996, 100 (27), 11355-11359 DOI: 10.1021/jp9608761.

69. Hu, Z.; Cai, T.; Chi, C. Thermoresponsive oligo(ethylene glycol)-methacrylate- based polymers and microgels. Soft Matter 2010, 6 (10), 2115-2123 DOI: 10.1039/B921150K.

70. Lutz, J.-F. Thermo-Switchable Materials Prepared Using the OEGMA-Platform. Advanced Materials 2011, 23 (19), 2237-2243 DOI: 10.1002/adma.201100597.

71. Seuring, J.; Agarwal, S. Polymers with Upper Critical Solution Temperature in Aqueous Solution. Macromolecular Rapid Communications 2012, 33 (22), 1898-1920 DOI: 10.1002/marc.201200433.

72. Hildebrand, V.; Laschewsky, A.; Pach, M.; Muller-Buschbaum, P.; Papadakis, C. M. Effect of the zwitterion structure on the thermo-responsive behaviour of poly(sulfobetaine methacrylates). Polymer Chemistry 2017, 8 (1), 310-322 DOI: 10.1039/C6PY01220E.

73. Hildebrand, V.; Laschewsky, A.; Wischerhoff, E. Modulating the solubility of zwitterionic poly((3-methacrylamidopropyl)ammonioalkane sulfonate)s in water and aqueous salt 
solutions via the spacer group separating the cationic and the anionic moieties. Polymer Chemistry 2016, 7 (3), 731-740 DOI: 10.1039/C5PY01642H.

74. Woodfield, P. A.; Zhu, Y. C.; Pei, Y. W.; Roth, P. J. Hydrophobically Modified Sulfobetaine Copolymers with Tunable Aqueous UCST through Postpolymerization Modification of Poly(pentafluorophenyl acrylate). Macromolecules 2014, 47 (2), 750-762 DOI: $10.1021 / \mathrm{ma} 402391 \mathrm{a}$.

75. Zhu, Y.; Noy, J.-M.; Lowe, A. B.; Roth, P. J. The synthesis and aqueous solution properties of sulfobutylbetaine (co)polymers: comparison of synthetic routes and tuneable upper critical solution temperatures. Polymer Chemistry 2015, 6 (31), 5705-5718 DOI: 10.1039/C5PY00160A.

76. Zhu, Y.; Batchelor, R.; Lowe, A. B.; Roth, P. J. Design of Thermoresponsive Polymers with Aqueous LCST, UCST, or Both: Modification of a Reactive Poly(2-vinyl-4,4dimethylazlactone) Scaffold. Macromolecules 2016, 49 (2), 672-680 DOI: 10.1021/acs.macromol.5b02056. 